\title{
Discurso territorial y práctica sectorial de las políticas socioambientales: un análisis del ecoturismo
}

\section{Territorial discourse and sectoral practice of socio-environmental policies: an analysis of ecotourism}

\author{
IRIS JoseFina LisCOVSKY* \\ Manuel Roberto Parra-Vázquez* \\ Eduardo Bello-Baltazar* \\ Ana Minerva ArCe-Ibarra**
}

\begin{abstract}
Ecotourism is studied from a territorial perspective as a socio-environmental policy promoted in the rural area. The role of ecotourism is analysed at the local scale in the two fisheries that implement it in a protected area natural. The territorial complexity starting from the resources that families have, the influences to mobilize them and the configured familiar strategy are addressed using a Livelihood framework. Participative community workshops are applied as a data collection technique using the reflection of participants. The results show that the lack of local particularities in the definition of policies and coercive aspects of the rural area can influence the success or failure of ecotourism. The need to generate comprehensive government programs is elucidated.
\end{abstract}

Keywords: territory, ecotourism, livelihood, policy, rural area.

\section{Resumen}

En este trabajo se estudia el ecoturismo desde una perspectiva territorial como una política socioambiental promovida en el área rural. Se analiza el papel del ecoturismo en la escala local en las dos pesquerías que lo implementan en un área natural protegida. Usando medios de vida se aborda la complejidad territorial partiendo de los recursos con los que cuentan las familias, las influencias para movilizarlos y la estrategia familiar que se configura. Se emplean los talleres comunitarios participativos como técnica de recolección de datos recurriendo a la reflexión de los participantes. Los resultados muestran que el desconocimiento de las particularidades locales en la definición de las políticas y los aspectos coercitivos del área rural pueden influir en el éxito o fracaso del ecoturismo. Se dilucida la necesidad de generar programas de gobierno integrales.

Palabras clave: territorio, ecoturismo, medios de vida, política, área rural.

* El Colegio de la Frontera Sur, Unidad San Cristóbal de Las Casas, México. Correos-e: iliscovsky@ecosur.mx, irisliscovsky@gmail.com; mparra@ecosur.mx y ebello@ecosur.mx.

** El Colegio de la Frontera Sur-Unidad Chetumal, México. Correo-e: aarce@ecosur.mx. 


\section{Introducción}

El proceso de globalización produce dos efectos destacables y opuestos: fragmenta la colectividad, lo cual "indica la existencia de una multiplicidad de prácticas y acciones colectivas dispersas, sin un orden racional aparente que las articule y que, por tanto, aunque posibilita la pluralidad de proyectos, dificulta a la vez su coexistencia, coincidencia e interferencia, restándoles poder y fuerza para transformar la realidad", y homogeniza las "normas de comportamiento y formas de interacción social por vía del consumo, las políticas económicas, la concepción de libre mercado, la privatización, la desregulación, la apertura” (Sánchez, 2007: 29-30). La fragmentación de la configuración institucional ha sido uno de los principales obstáculos del desarrollo sustentable, ante lo cual se requiere que se consideren los componentes social, económico y ambiental de manera conjunta en las políticas (Chambers y Green, 2005) adoptando una visión realmente territorial, donde sea central la compatibilidad de las propuestas con los medios de vida locales.

El planteamiento del ecoturismo es una de las propuestas globales que no considera la heterogeneidad estructural local y, consecuentemente, muchas veces no atiende las necesidades locales (Córdoba et al., 2004), con lo cual, los programas de desarrollo eluden evaluar sus efectos territoriales, imprescindibles al considerar el desarrollo territorial (Montañez y Delgado, 1998). Esta actividad ha sido ampliamente implementada en áreas naturales protegidas (ANP) para promover su protección (Bringas y Ojeda, 2000), donde a través de la conservación de los ecosistemas y servicios se pretende mantener los medios de vida locales (Naughton $e t$ al., 2005). Sin embargo, para promover la conservación se debe permitir obtener fuentes de ingresos opcionales en el área rural y una rentabilidad mayor a otros usos del suelo (Bringas y Ojeda, 2000) y, además, "cuando se aplica un discurso global (el desarrollo sostenible por la vía de estrategias como el ecoturismo) mediante políticas y proyectos concretos (como en este caso son las ANP), existen, a nivel local, unas implicaciones concretas" (Córdoba et al., 2004: 68).

Los cambios de la actividad turística se conciben en el orden mundial, sin embargo, sus expresiones específicas son observables en el área local (Bringas y González, 2004). Dadas sus diversas formas en la implementación, se diferencia el ecoturismo de empresas del comunitario (Scheyvens, 1999). Contrariamente al postulado teórico, las más de las veces, el ecoturismo atrae visitantes desconocedores de una verdadera conciencia ambiental que se introducen en zonas frágiles y remotas, algunas de ellas las más importantes áreas de diversidad biológica y cultural, siendo los principales beneficios económicos cautivados por cadenas y redes inter- 
nacionales, mientras que los perjuicios los absorben las comunidades (McLaren, 1998).

Las contradicciones teoría-práctica del ecoturismo son numerosas siguiendo una "forma irreflexiva desde imperativos globales [...] sobre comunidades locales cuya complejidad se simplifica de forma abusiva y precipitada" (Córdoba et al., 2004: 75). Así, comienzan a manifestarse temas poco indagados en relación con el alcance práctico del ecoturismo (Liu, 2003) ya que, a pesar de ser claras las intenciones de esta política ambiental, los métodos y la aplicación han sido poco estudiados (Salinas y La O, 2006) y mal manejado puede desencadenar los mismos efectos indeseables del turismo en masas (Bringas y Ojeda, 2000). Por ello, son necesarios estudios que enfaticen el análisis de la complejidad local desde la perspectiva interna, para comprender los procesos que se desencadenan en esta escala y aportar información sobre las posibles causas de la generalizada falta de éxito de los emprendimientos de ecoturismo.

Este estudio se circunscribe a un ANP, dado que a pesar de la amplia promoción que el ecoturismo recibe en estas zonas, se desconoce si se logran los objetivos que desde las instituciones gubernamentales se promocionan para su implementación. Un ejemplo de esta promoción se observa en la Comisión Nacional de Áreas Naturales Protegidas (Conanp), particularmente en su Programa Nacional de Áreas Naturales Protegidas 2007-2012, donde plantea "que el turismo se siga desarrollando bajo un esquema sustentable a favor de la preservación del patrimonio natural y de las comunidades locales como beneficiarios directos en el entorno de las Áreas Protegidas Federales y otras modalidades de conservación" (Conanp, 2007: 22, 25).

El presente estudio parte de la propuesta de bases conceptuales del ecoturismo que consideran la definición de área rural y su relación con el turismo rural. La propuesta teórica se utiliza para valorar el papel del ecoturismo en dos rancherías que lo implementan actualmente en la Reserva de la Biósfera La Encrucijada (Rebien), partiendo de un análisis multidimensional comunitario empleando medios de vida.

\section{Delimitación teórica del ecoturismo como base de su implementación}

El ecoturismo se ha adoptado como parte de las políticas ambientales gubernamentales para ser implementado en el área rural. La falta de consenso en su conceptualización no sólo implica aspectos de índole teórica, sino, sobre todo, efectos en la práctica, ya que se ha utilizado el término "ecoturismo" de manera indiscriminada enfatizando en los aspectos benéficos para el medio ambiente, lo cual no necesariamente es 
cierto (Bringas y Ojeda, 2000). En este sentido, y como parte de una construcción teórica de las bases del ecoturismo, es necesario revisar y considerar las definiciones de área rural y turismo rural.

No obstante lo anterior, existe dificultad para definir o delimitar el concepto de área rural, lo cual se atribuye, básicamente, a la heterogeneidad de condiciones que abarca este concepto (Holland et al., 2003; Ashley y Maxwell, 2002). Para los fines de este trabajo, se considera un área rural como

el espacio donde los asentamientos y la infraestructura humana ocupan únicamente pequeños parches del terreno, la mayoría de los cuales son dominados por campos y pastos, maderas y bosques, agua, montañas y desierto. Ellos son también lugares donde la mayoría de la gente pasa la mayor parte de su tiempo de trabajo en granjas; donde la tierra es abundante y barata; donde la transacción de costos es alta; y donde las condiciones políticas son más dificultosas (Ashley y Maxwell, 2002: 1).

A esto se añade que las principales actividades humanas en este ámbito son las primarias (pecuarias, acuicultura, pesca y forestales, entre las más importantes) y que el uso del recurso agua, como medio productivo, es esencial. Entre los atributos más sobresalientes de las zonas rurales se citan el aislamiento, la lejanía, la baja densidad demográfica y las escasas prestaciones sociales (Paniagua, 2008).

Al considerar la ruralidad como eje rector de la clasificación de turismo, se aborda el estudio desde una perspectiva territorial. Considerando al territorio "como espacio de articulación de estrategias de desarrollo se presenta como objeto de acciones, tanto de iniciativas de la propia sociedad, a través de movimientos sociales, organizaciones no gubernamentales y entidades privadas, como de políticas públicas", desde esta perspectiva se "relaciona espacio, recursos naturales, sociedad y poder" (Flores, 2007: 35).

Así, adoptando el criterio de ruralidad expuesto, el turismo rural se caracteriza por las particularidades del área, en contraposición con el turismo que se realiza en las urbes. Esta postura de la centralidad en el área sobre la actividad para definir al turismo rural coincide con algunas postulaciones previas (Martínez, 2005, en Oliveira y González, 2008: 723).

Por otro lado, los límites entre turismo rural y ecoturismo están poco definidos y consensuados (Bringas y Ojeda, 2000). Entre ambos, el único factor de coincidencia reconocido es que se considera turismo basado en la naturaleza en contraposición con el turismo de masas. Esta falta de delimitación lleva a inconsistencias en la práctica, por lo que un esfuerzo teórico en tal sentido es necesario. 
Existe alto consenso para considerar al turismo rural como inclusivo del agroturismo (Oliveira y González, 2008) y éste último del turismo en granjas (Bojnec, 2006), destacando las actividades que se realizan en el ámbito primario de la economía (Oliveira y González, 2008). Otros autores lo caracterizan más ampliamente: se contrapone al turismo en masa; utiliza, respeta y cuida los recursos naturales, patrimoniales y culturales; supone un mecanismo de desarrollo para las economías locales; e incluye un componente educativo para el visitante (Mediano y Vicente, 2002). Considerando esta última concepción, es notable la semejanza con la definición más ampliamente difundida de ecoturismo acuñada por Ceballos (1998: 7), la cual incluye todos los aspectos antes mencionados y agrega el involucramiento activo de las poblaciones locales. Así, algunos autores consideran al turismo rural como inclusivo del ecoturismo (Blanco y Benayas, 1994, en Mediano y Vicente, 2002: 27). Los aspectos centrales para el desarrollo del ecoturismo son: 1) contar con zonas ricas en biodiversidad y poco afectadas por la acción antrópica (Burgueño 2005), 2) enfatizar en la educación y 3) alcanzar la sustentabilidad (Burton, 1998).

Con la información precedente se construyó y se proponen dos modelos explicativos sobre la delimitación entre turismo rural y ecoturismo (cuadro 1). En el primer modelo el criterio de clasificación son las actividades, donde el turismo rural y el ecoturismo sólo comparten el hecho de considerarse turismo basado en la naturaleza. Bajo este modelo, el ecoturismo se asienta sobre las bases de la sustentabilidad, término que en la práctica ha resultado poco operativo (McLaren, 1998) y, bajo este criterio, es posible la introducción de actores no necesariamente locales en relación con el desarrollo, control y apropiación de los beneficios. Mientras que en el segundo modelo se enfatiza en las características del área rural, así, el ecoturismo se presenta como un subsistema especializado del turismo rural, donde las oportunidades deben estar dirigidas al sector rural y los habitantes locales deben ser centrales en el desarrollo de las actividades sustentables, el control y los beneficios del ecoturismo. Se destaca que independientemente de los criterios de clasificación adoptados, las actividades específicas para el ecoturismo o los otros tipos de turismo rural (agroturismo y turismo en granjas) no varían. En el presente estudio se asume el segundo modelo.

\section{Contexto de la investigación}

En el ámbito global, durante las décadas de los ochenta y noventa numerosas organizaciones internacionales apoyaron la implementación de iniciativas ambientales, como la creación de ANP con fines de conservación 


\section{Cuadro 1 \\ Modelos que relacionan el turismo rural y el ecoturismo}

\begin{tabular}{|c|c|c|c|}
\hline \multicolumn{2}{|c|}{$\begin{array}{c}\text { Modelo 1: centrado en las actividades de } \\
\text { atracción turística }\end{array}$} & \multicolumn{2}{|c|}{$\begin{array}{c}\text { Modelo 2: centrado en las potencialidades } \\
\text { del área rural }\end{array}$} \\
\hline Turismo rural & Ecoturismo & Turi & mo rural \\
\hline $\begin{array}{l}\text { El turista } \\
\text { presencia o } \\
\text { participa de } \\
\text { actividades } \\
\text { económicas } \\
\text { primarias }\end{array}$ & $\begin{array}{l}\text { El turista realiza actividades } \\
\text { de bajo impacto socio- } \\
\text { cultural y ambiental }\end{array}$ & $\begin{array}{l}\text { Promueve econom } \\
\text { pluriactividad de e } \\
\text { baja afluencia turís } \\
\text { recursos naturales, } \\
\text { culturales; incorpo }\end{array}$ & $\begin{array}{l}\text { as locales y } \\
\text { trategias familiares; } \\
\text { ica; interés por } \\
\text { patrimoniales y } \\
\text { a educación }\end{array}$ \\
\hline Agroturismo & $\begin{array}{ll}\text { manejado por } & \text { manejado } \\
\text { empresas u } & \text { por } \\
\text { organizaciones } & \text { comunidad } \\
\text { externas } & \end{array}$ & $\begin{array}{l}\text { Agroturismo y } \\
\text { turismo en } \\
\text { granjas }\end{array}$ & Ecoturismo \\
\hline $\begin{array}{l}\text { Turismo en } \\
\text { granjas }\end{array}$ & & $\begin{array}{l}\text { Los actores } \\
\text { locales comparten } \\
\text { su experiencia en } \\
\text { las actividades } \\
\text { económicas } \\
\text { primarias }\end{array}$ & $\begin{array}{l}\text { Los actores locales } \\
\text { proponen actividades } \\
\text { de bajo impacto } \\
\text { sociocultural y } \\
\text { ambiental }\end{array}$ \\
\hline
\end{tabular}

Fuente: Elaboración propia.

y para mejorar las condiciones de vida de las poblaciones (Daltabuit et al., 2006). La Rebien se creó en México en el año 1972 bajo la denominación de Área Natural y Típica del Estado de Chiapas Tipo Ecológico Manglar Zapotón con una extensión de 2,500 ha, en 1995 el área se amplía a 144,868 ha y se recategoriza como Reserva de la Biosfera (Carabias et al., 1999). Actualmente, forma parte de las 36 áreas naturales protegidas prioritarias en el sistema de atención y administración del Instituto Nacional de Ecología, integra parte del Corredor Biológico Mesoamericano (Carabias et al., 1999), desde 1996 se le considera un sitio Ramsar (Convención de Ramsar, 2010) y una de las 152 regiones terrestres prioritarias de México (Arriaga et al., 2000), lo cual es referencia de la importancia del área en cuanto a su biodiversidad.

De las formaciones vegetales presentes en la Rebien se destacan los manglares, por su intervención en la regulación de los ciclos ecológicos, la retención de suelos, la producción de nutrientes y por su actividad como trampa de contaminantes, a cuyos márgenes las poblaciones humanas tradicionalmente han desarrollado actividades de pesca, favorecida por la alta productividad de estos sistemas costeros (Carabias et al., 1999). Sumado a los eventos climáticos que impactan en el área, en Chiapas se registró una tasa de transformación anual de los manglares de 838 ha/ 
año, en un área total reportada de 43,832 ha para el periodo 1988-1993 (March y Flamenco, 1996: 32), con lo cual, ante la posibilidad de una tasa sostenida de transformación, esta cobertura vegetal se encuentra en serio riesgo y con ello el sustento de las poblaciones locales.

El ecoturismo es promovido por la Conanp en las ANP. En la Rebien se considera incipiente y se ha desarrollado en dos rancherías pesqueras: La Palma (LP) en el municipio de Acapetahua y El Castaño (EC) en el municipio de Mapastepec. LP se ubica en la zona núcleo de la Rebien, en su área central, y EC en la zona de amortiguamiento de la Rebien, en el noroeste de la zona núcleo (Tovilla, 2007), donde el territorio productivo lo constituye el medio acuático (figura I). Se destacan dos factores clave para la implementación de iniciativas de ecoturismo en esta ANP: desde el punto de vista natural, el atractivo para los visitantes que pueden apreciar los manglares más altos de la costa del océano Pacífico, y desde lo socioeconómico el producto pesquero se encuentra en una sostenida disminución (Carabias et al., 1999), lo que lleva a la necesidad de buscar soluciones a la crítica situación económica familiar.

\section{Figura I}

Área de estudio: El Castaño (municipio de Mapastepec) y La Palma (municipio de Acapetahua)

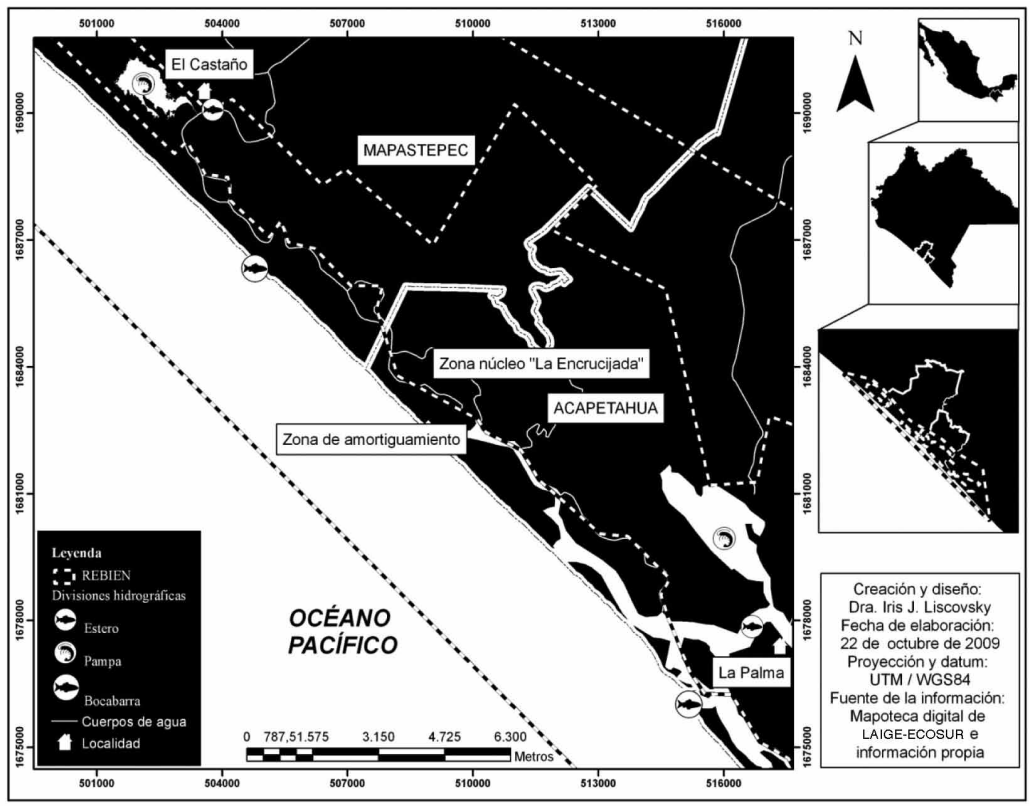

Fuente: Elaboración propia. 


\section{Metodología}

\subsection{Enfoque de estudio}

El estudio multidimensional del ecoturismo a nivel comunitario se abordó desde el marco de medios de vida (MV). Este marco intenta superar el reduccionismo y simplificación imperante al tratar el empleo como una medida de la disminución de la pobreza, así, se incluye el empleo como una variable y se aborda la complejidad y la diversidad de situaciones (Chambers, 1995, 2004). Además, el Mv se centra en la perspectiva de la gente local, por lo que el conocimiento tradicional es esencial en su aplicación. Con esto, la presente investigación también hace una integración del conocimiento obtenido por métodos científicos con el conocimiento local o tradicional (Arce y Gastelú, 2007; Arce y Charles, 2008).

Los principales elementos de MV son: 1) los activos o capitales, que representan los recursos que un individuo, familia o comunidad poseen, y que se clasifican en humano, social, natural, físico y financiero, 2) el contexto (vulnerabilidad, políticas, estructura, instituciones), que influye en las restricciones y oportunidades para la familia y la comunidad, y 3) las estrategias que son la forma en que las familias movilizan sus activos para vivir y alcanzar sus objetivos de futuro (DFID, 1999). Cada capital hace alusión a características específicas (DFID, 1999), para las cuales se identificaron las variables más pertinentes para considerarse en relación con la planeación (anexo I).

La movilización de los recursos con los que cuentan las familias está influida por el contexto. El contexto de vulnerabilidad se define por las tendencias, eventualidades puntuales y cambios (positivos o negativos) sobre los cuales las familias tienen escaso o nulo control. El contexto de las estructuras, políticas y procesos influyen en la disposición de los recursos con que cuentan las familias. Todos estos aspectos inciden en la constitución de la estrategia familiar, que es el resultado de la combinación de los elementos de los medios de vida. Desde esta perspectiva es posible analizar las relaciones entre los recursos que poseen las familias, el contexto en el que se hace uso de esos recursos, las estrategias que surgen de esa interacción y los resultados.

\subsection{Recopilación y análisis de los datos}

Los talleres fundados en Mv y su sistematización se realizaron con base en el Manual de diagnóstico participativo para la planeación comunitaria (Parra et al., 2011), el cual se emplea en el equipo de investigación Modos de vida e innovación territorial (El Colegio de la Frontera Sur, San Cris- 
tóbal de Las Casas) como herramienta operativa desde el año 2005. Los talleres fueron guiados por facilitadores capacitados para dicho fin y se desarrollaron a nivel comunitario en marzo de 2009, ante la presencia de miembros de las rancherías de EC y LP. En los talleres se priorizó la participación de personas que pudieran aportar conocimiento local histórico y actual, así, se reflexionó con hombres y mujeres, jóvenes económicamente activos, adultos y gente mayor.

El trabajo de campo se dividió en 5 fases: 1) invitación a las comunidades para participar en el taller; 2) capacitación de facilitadores y cofacilitadores; 3) trabajo de gabinete con fuentes secundarias; 4) transectos por el medio natural y social y encuestas con informantes clave locales, y 5) realización de los talleres diagnóstico comunitarios participativos, trabajo con grupos focales y sociabilización de los datos (Parra et al., 2011).

La información obtenida en el análisis de los capitales se estudió empleando escalas (anexo I). El valor obtenido para cada capital permite una comprensión general de las prioridades en el ámbito local y posibilita la comparación entre diversos sitios. Los resultados se presentaron públicamente en las comunidades, con invitación abierta, con el fin de corroborar las interpretaciones de los datos.

El capital natural se abordó realizando un recorrido por el medio acuático con un informante clave, para identificar, delimitar y describir las zonas hidrográficas reconocidas localmente. Durante el taller se realizaron mapas y tablas de tipo de uso del territorio del tipo diacrónico para analizar los cambios en el territorio.

Los elementos del capital físico se valoraron con base en la metodología propuesta por Batista et al. (1994: 339), sumando la valoración regular en los casos donde existieron observaciones buenas y malas en relación con alguna de las categorías analizadas. Se combinaron los resultados de la evaluación externa (facilitadores) e interna (participantes del taller) para definir las prioridades locales. Las cuatro tipologías resultantes de esta metodología se interpretaron como: 1) las evaluaciones externa e interna son coincidentes y positivas (bienestar); 2) la evaluación externa es negativa, sin embargo las personas han creado mecanismos o estrategias que hacen que lo valoren como positivo (adaptación); 3) la evaluación externa es positiva, pero no es adecuado para las preferencias y necesidades locales (disonancia), y 4) las evaluaciones externa e interna son coincidentes y negativas (malestar).

Para el capital financiero se analizaron los resultados (ingreso y egreso) y el sistema de financiamiento (capacidad de inversión), los cuales en conjunto constituyen la estrategia económica. Para la interpretación de los ingresos se consideraron las líneas de pobreza calculadas para el año 2008 en México (Coneval, 2009): pobreza alimentaria 50,881.68 pesos; 
pobreza de capacidades $60,157.44$ pesos; pobreza de patrimonio $92,329.92$ pesos (calculadas para una familia promedio de seis personas, según información de los participantes del taller).

En el capital social se analizó la densidad de las redes sociales, la cual se consideró un indicador explicativo de la estructura social. El valor de densidad de una red representa las relaciones existentes en comparación con las potenciales. Se asume que idealmente se espera un alto número de relaciones, lo cual imprime mayor estabilidad al sistema social (la centralidad en uno o pocos nodos hace que de su existencia dependa el mantenimiento de la red) y representa menor sectorización y desintegración (estructuralmente ideal para implementar programas integrales). Para los fines comparativos se construyó una escala de valoración empírica, basada en el análisis de resultados obtenidos en diferentes zonas y grupos sociales de Chiapas (anexo I).

El capital humano se abordó por medio de la indagación de las estadísticas oficiales (INEGI-ITER, 2005; INEGI-Inafed, 2000). Esa información se contrastó durante el taller participativo con las opiniones de los pobladores en relación con los diversos servicios e infraestructura y la medida en que los mismos responden a sus necesidades.

La vulnerabilidad, las estructuras, los procesos y las políticas se abordaron transversalmente a lo largo de los talleres, indagando para cada capital las condiciones contextuales relevantes que se relacionan a los mismos. Por medio de las relatorías de cada grupo focal se identificaron las tendencias, eventualidades y cambios, se delimitaron los procesos más relevantes atendiendo a su reiteración a lo largo de los diversos grupos de trabajo y se reconocieron las estructuras y políticas asociadas a esos procesos.

Para el análisis de las estrategias se utilizaron datos de los diversos grupos focales, los cuales posteriormente se combinaron. En el capital natural se abordó la estrategia para el uso del territorio, en el financiero la estrategia económica y el análisis de las relaciones sociales y el proceso de migración permitió identificar los componentes familiares y comunitarios que se combinan con las estrategias anteriores.

Un factor limitante de los talleres es que no se ahonda en las particularidades individuales de las familias, sino que se construye un esquema explicativo de cómo las familias de la comunidad construyen su día a día, sin por ello considerar a esta unidad de análisis como "tipo" u homogénea.

La información de los talleres se complementó con la indagación de fuentes secundarias y los aspectos históricos locales se obtuvieron por medio de entrevistas abiertas con informantes clave. Además, para los datos del ecoturismo también se realizaron entrevistas abiertas con informantes clave, dado que el ecoturismo como alternativa local no fue 
priorizado durante el taller, buscando que surgiera naturalmente el planteamiento de su papel en la escala local.

\section{Resultados}

El sitio de estudio se encuentra en la zona costera de Chiapas, inserto en un sistema de humedales, con predominancia de bosques de manglar. En esta zona los habitantes viven de la pesca ya que su territorio principalmente es acuático, a diferencia del resto de la región Soconusco, donde las actividades rurales se centran en la agricultura y la ganadería.

El sitio donde se encuentra la ranchería LP era un lugar de paso entre el embarcadero y los asentamientos cercanos a la playa, como Barra $\mathrm{Za}-$ capulco. El asentamiento se funda entre 1870 y 1878 con familias dedicadas a la agricultura, pesca y caza, sobre todo para la subsistencia. Paulatinamente, y dado el creciente auge de la pesca, desde la década de los veinte se fueron asentando en el sitio pobladores de origen regional, que se dedicaban a la pesca local y a la agricultura, esta última principalmente en la zona entre Acapetahua y el embarcadero Las Garzas. Estas dos actividades constituían la base de sustento de las familias. La ranchería se reconoce formalmente entre 1935 y 1937, después se constituye la cooperativa de pesca en el año 1945. Poco a poco la gente se aboca con exclusividad a la producción pesquera, dado su alto rendimiento, sobre todo en relación con el camarón. La principal área de pesca de camarón lo constituía la laguna de Chantuto, la cual era compartida en la explotación con la cooperativa de pesca de Barra Zacapulco. La abundante migración a lugares cercanos a esa laguna desencadenó en 1992 conflictos en relación con el derecho de pesca que culminaron en confrontaciones armadas y la expulsión de los miembros de la cooperativa de pesca de LP. De esta forma, los pescadores de la ranchería se recluyeron a lugares de menor producción, con el consecuente efecto en la economía familiar. Debido a ello, fueron necesarias nuevas alternativas. La Iglesia católica desempeñó un papel importante en este sentido, a través de la asociación Indígenas de la Sierra Madre de Motozintla "San Isidro Labrador" (Ismam), apoyando a la comunidad a través de su programa de formación Trabajo Común Organizado y planificando nuevos proyectos productivos a partir del Centro de Agroecología San Francisco de Asís (CASFA). Así, entre 1993 y 1995 se planificó y desarrolló un proyecto de cría y engorda de camarón, el cual no prosperó, sobre todo por la falta de formación en relación con el proceso de producción artificial y el mantenimiento de la infraestructura. A partir de ese primer grupo conformado, Ismam y CASFA siguen apoyando a la comunidad promoviendo esta vez la implementación de un centro turístico, ante lo cual se constituye el Grupo Ecológico San Carlos, que 
inicio sus actividades de organización y planificación alrededor de 1996 y se conformó legalmente como cooperativa en 2002.

Las tierras correspondientes a EC fueron compradas por una familia de El Manguito (comunidad vecina), así se creó el asentamiento en 1958. El principal centro urbano con el que se comunicó desde un principio la población de EC fue la cabecera municipal de Mapastepec, principalmente para la compra y venta de alimentos. Próximo al asentamiento y cercano a 1975 se asienta en la isla Las Morenas una familia proveniente del estado de Guerrero. Debido a la necesidad de recibir servicios básicos (como luz, agua, salud y educación), ambas familias planificaron concretar un asentamiento único. Así, aproximadamente en 1980 la familia residente en Las Morenas compró terrenos en EC. Los habitantes practicaban la pesca, la agricultura y la ganadería a pequeña escala. La cooperativa de pesca local surge como una iniciativa para defender los recursos pesqueros de su territorio de los pescadores oportunistas, donde en el proceso de legalización los apoya un maestro rural de la zona, para finalmente en el año 1988 constituirse legalmente. La creciente disminución del producto pesquero, debido a modificaciones ambientales en la zona alta de la cuenca, y el impacto del huracán Stan en 1988, que agravó las condiciones ambientales, llevaron a la necesidad de buscar nuevas alternativas. Por iniciativa de uno de los pobladores, quién trabajó temporalmente en la Conanp, se comenzó a evaluar la posibilidad de desarrollar un centro turístico local. El interés estaba puesto en mejorar las condiciones de vida de las familias, evitar la migración de la gente joven y promover el equilibrio ambiental. La propuesta se discutió y planificó durante dos a tres años, para finalmente en el año 2005 constituir el Grupo Ecoturístico Costa Verde.

\subsection{Medios de vida}

\subsubsection{Capital natural}

El sistema de humedal se caracteriza por la abundancia del recurso agua. En el ámbito local donde se construye una división ambiental en función de las características hidrográficas, lo cual permite caracterizar a los diversos ambientes. De acuerdo con ello, se identifican tres zonas principales: estero, pampa y bocabarra (figura I). Las tres áreas son de uso con fines de pesca, siendo las pampas las áreas predominantemente productivas de camarón. Otras actividades desarrolladas en el territorio son el transporte acuático por el estero, actualmente también realizado como recorrido para visitantes y el uso de la playa para recreación. 
La madera es un recurso de importancia en los medios de vida locales. La actividad extractiva de madera está restringida por las regulaciones de la Rebien, por lo que en la actualidad no es una práctica frecuente. El conocimiento local del entorno ambiental se distingue en la descripción de la utilidad de diversas especies. El mangle se reconoce como útil para la construcción de casas y postes. El botoncillo, el mezquite y el mahahui se consideran apropiados para muebles. Una actividad actual es la extracción de leña para la cocina, este recurso se encuentra limitado al uso doméstico y en caso de utilizarse para fines diferentes al autoabasto de las familias, se debe contar con permisos especiales, dada la ubicación de las rancherías en un ANP.

Permisos y concesiones de las instituciones reguladoras de pesca permiten la extracción de peces y camarón. Mientras que otros animales que antes eran usados para el consumo familiar (como algunos reptiles) se encuentran restringidos por las prioridades de conservación de la zona.

En el ámbito local se identifican modificaciones de las condiciones ambientales. Debido principalmente a las actividades productivas que recurren a la deforestación y a las políticas de canalización de los cursos de agua en la cuenca alta, ha aumentado el arrastre de suelo con su consecuente modificación de granulosidad (partículas más grandes), color (se observan cambios de negro a marrón, lo cual implica cambios en la composición química) y fluidez (menos fluidos) en la cuenca baja. Paralelamente, la abundancia y distribución de las especies de fauna se ha modificado, en parte debido a la alteración ambiental. Como consecuencia, la pesca como recurso esencial de los medios de vida ha tenido un deterioro significativo.

En LP se ha observado una alteración de la abundancia del mangle, mientras que en EC se identifican alteraciones también en cuanto a la distribución de las diversas especies de esta conformación vegetal. En ambas rancherías se han identificado fuentes de contaminación vía las corrientes de agua dulce (principalmente debido a agroquímicos usados en agricultura), mientras que no se reconocen fuentes de contaminación del aire, además, en LP las dificultades para transportar la basura y el inadecuado sistema de recolección hacen que a nivel local éste sea un problema.

El acceso a los recursos naturales está regulado por normativas externas, principalmente las de Conanp y Profepa, sin embargo, en EC esas normativas coinciden con las reglas internas comunitarias en pos del cuidado de su territorio. Las poblaciones previas a la creación de la reserva son permitidas, no así la creación de nuevos asentamientos. Las normativas gubernamentales son más restrictivas para las comunidades de la zona núcleo que para las de la zona de amortiguamiento de la reserva. 
En LP el uso de los recursos es principalmente extractivo (pesca), mientras que en EC se combina con la producción primaria para el autoabasto. Así, las familias de LP son altamente dependientes de los recursos naturales y las de EC son semidependientes, lo cual también se relaciona con la ubicación que ocupan en la reserva y la disponibilidad de tierra. En ambas rancherías el territorio donde se desarrolla la pesca es acuático y de uso colectivo, las propiedades de tierra de los pobladores se limitan a patios donde se ubican los hogares. En EC algunas familias cuentan además con un máximo de 2 ha de tierra por familia.

\subsubsection{Capital físico}

El agua en ambas comunidades se extrae de pozos, y a pesar de que se trata de un sistema de humedal, puede ser escasa en ciertas épocas del año, donde los habitantes deben recurrir al agua del estero o comprar agua embotellada para el consumo. La diferencia entre comunidades se da por la amplia cobertura que alcanza en LP, mientras que en EC no llega a todas las familias, aunque ésa sea la intención.

Todos los hogares cuentan con pozos donde se descargan las aguas residuales. Si bien esta condición no es la óptima por la superficialidad de las aguas subterráneas, desde la perspectiva de los pobladores sería peor contar con un drenaje que descargue los residuos en el estero, sistema base de su principal actividad económica.

En relación con la energía, suele emplearse leña para la cocina y se cuenta con sistema eléctrico para la iluminación y electrodomésticos. En EC la calidad de la electricidad es adecuada sólo para el uso doméstico y las líneas tienen una cobertura parcial a los hogares. En LP, si bien la calidad es mejor que en la ranchería anterior, el uso para fines productivos es limitado y la cobertura es total. En ambas rancherías el principal problema lo ocasiona la interrupción del servicio en épocas de tormenta y la falta de respuesta o tardanza de las instituciones responsables para restituirlo. Sumado a ello, los recibos de luz suelen ser muy caros, lo cual es un constante reclamo de los pobladores.

Los niveles educativos locales son diferentes. En LP se cuenta con edificios de preescolar, primaria y secundaria, mientras que en EC sólo con un edificio donde se desarrollan los niveles de preescolar y primaria.

En relación con la salud, las condiciones son muy diferenciadas. En LP se cuenta con una clínica del Instituto Mexicano del Seguro Social (IMSs), médico de lunes a viernes y enfermera toda la semana, sin embargo, la carencia de medicinas, la falta de médico los fines de semana y la necesidad de trasladarse a la cabecera municipal u otros centros de mayor complejidad regional para realizar estudios y análisis son puntos de dis- 
conformidad. En EC se construyó una clínica con esfuerzo, fondos comunitarios y donaciones donde llegaría personal médico de la Caravana Acuática inaugurada en 2007, para atender a las comunidades más alejadas de centros urbanos, sin embargo, la frecuencia y constancia de este servicio se ha llegado a espaciar en lapsos de dos meses o más y no se cuenta localmente con medicinas.

Las vías de comunicación al exterior están representadas por la vía acuática (estero), y en Ec principalmente por un camino de terracería que se deteriora anualmente en las épocas de lluvia, lo cual representa un problema dada la falta de mantenimiento del mismo. Las vías de comunicación locales son sobre todo calles y en menor medida veredas, todas de tierra.

El transporte es casi exclusivamente privado en EC (a excepción de viajes especiales de la línea Mapastepec-Roberto Barrios) y pocas personas cuentan con medios de movilidad propios. Es privado y público en LP, donde los costos del transporte público son elevados desde la perspectiva de los pobladores, y a su vez imprescindibles para la provisión de alimentos, insumos o acceso a los sistemas de salud y educación.

En ambas rancherías existen medios de información principalmente regionales y nacionales (radio y televisión) y de comunicación deficientes (teléfono). Sólo en LP hay sistema de internet, pero inestable y de baja calidad.

En ambas comunidades se cuenta con infraestructura de las cooperativas de pesca constituida básicamente por un recinto para reuniones, sitio de recepción del producto pesquero y un muelle. Las herramientas productivas son sobre todo manuales (herramientas para la pesca) y la pesca se realiza en general en cayucos a motor. Es un punto de coincidencia considerar que no se requieren herramientas productivas, sino proyectos para recuperar la pesca.

Los centros de reunión son más numerosos en LP que en EC, sin embargo, en la primera ranchería son principalmente de información, mientras que en la segunda también son de participación. En ambas se encuentran sitios de reunión con fines deportivos, religiosos, productivos y comunitarios (asambleas y comités).

Ambas cooperativas de ecoturismo cuentan con servicio de alojamiento, centro de interpretación ambiental y lancha para recorridos. LP además cuenta con un restaurante y EC con diversos transportes acuáticos para alquiler.

De la combinación de los datos observados por los facilitadores (evaluación externa) y los aportados por los participantes (evaluación interna) de los talleres, se dedujeron las áreas prioritarias de las problemáticas locales (cuadro 2). 
Las variables incluidas en el rango entre disonancia y malestar (cuadro 2) son las que deberían recibir atención urgente, ya que son los principales criterios de disconformidad, siendo prioritarios en ambos casos salud, educación y la mejoría de las vías de comunicación, asimismo, la provisión de agua y su calidad también es importante en ambas. En EC además se suman el reclamo de energía adecuada para uso productivo y su respec-

\section{Cuadro 2}

Comparación entre las evaluaciones externa e interna de los elementos del capital físico

\begin{tabular}{|c|c|c|c|c|c|}
\hline & & & & valuación extern & \\
\hline & Valoración & & Bueno & Regular & Malo \\
\hline & & & Bienestar & & Adaptación \\
\hline & & Bueno & $\begin{array}{l}\text { Herramientas } \\
\text { para la } \\
\text { producción }\end{array}$ & & \\
\hline & El Castaño & Regular & & $\begin{array}{l}\text { Sistema de } \\
\text { desecho de } \\
\text { aguas } \\
\text { residuales }\end{array}$ & \\
\hline & & & Disonancia & & Malestar \\
\hline Evaluación & & Malo & & $\begin{array}{l}\text { Agua, energía, } \\
\text { educación, } \\
\text { salud, vías } \\
\text { interlocales }\end{array}$ & \\
\hline interna & & & Bienestar & & Adaptación \\
\hline & & Bueno & $\begin{array}{l}\text { Herramientas } \\
\text { para la } \\
\text { producción }\end{array}$ & & \\
\hline & & Regular & Energía & & \\
\hline & La Palma & & Disonancia & & Malestar \\
\hline & & Malo & Agua & $\begin{array}{l}\text { Sistema de } \\
\text { desecho de } \\
\text { aguas } \\
\text { residuales, } \\
\text { educación, } \\
\text { salud, vías } \\
\text { interlocales }\end{array}$ & \\
\hline
\end{tabular}

Fuente: Elaboración propia con base en la metodología de Batista-Foguet et al. (1994: 339). 
tivo servicio de mantenimiento, y en LP un sistema apropiado de tratamiento de aguas residuales.

\subsubsection{Capital financiero}

En las rancherías foco de este estudio, los ingresos superan notablemente las tres líneas de pobreza calculadas para el año 2008. Sin embargo, los egresos son igualmente muy elevados (gráfica I).

Los principales ingresos de las familias de ambas rancherías provienen del sector productivo, donde la actividad casi exclusiva es la pesca. Al considerar sólo los ingresos productivos, los ingresos familiares anuales quedan por debajo de la línea de pobreza de patrimonio (EC: 89,544 pesos; LP: 64,300 pesos), que se supera cuando se incorporan otros ingresos como préstamos, créditos, remesas y jornales (EC: 27,480 pesos; LP: 51,800 pesos), los cuales no son estables. Los apoyos gubernamentales y los otros ingresos conforman un alto porcentaje del ingreso total anual (EC: 43\%; LP: 58\%; gráfica I).

Los principales egresos se corresponden con los destinados a cubrir necesidades básicas, como alimento, educación, salud, calzado y vestido. En el rubro otros egresos familiares se incluyeron los viajes, los cuales encarecen notablemente los gastos de las familias, sin embargo son imprescindibles dado que se requieren para realizar trámites, provisión de alimentos, asistir al médico o a niveles educativos que no se encuentran localmente. También los gastos por insumos productivos para la pesca son elevados, ello se debe principalmente al gasto de gasolina para los motores de cayucos y lanchas. Por último, los aportes comunitarios o religiosos son el rubro menos demandante en la economía familiar (gráfica I).

Sumado a las condiciones económicas anteriores, las capacidades de financiamiento de las familias son muy reducidas, las cuales están dadas por las posibles fuentes de inversión. Al indagar sobre estas últimas, se encontró que en EC es posible acceder hasta un nivel de préstamos entre familiares o amigos, y en LP hasta un nivel de crédito por parte de organismos gubernamentales para pequeños emprendimientos (gráfica II).

Finalmente, interesa analizar la distribución de las actividades económicas en el ańo (cuadro 3), enfatizando en la principal actividad económica local (pesca) y en la nueva alternativa económica (ecoturismo). Localmente, se clasificaron los meses en bueno, regular o malo por actividad. La pesca se califica, en primera medida, por las etapas anuales en las que hay mayor disposición de peces y/o camarón, o mayor demanda del mercado. Las actividades turísticas, actualmente incipientes, se califican por la afluencia de turistas, donde la mayor demanda se identifica en los periodos vacacionales (cuadro 3). 


\section{Gráfica I \\ Análisis de ingresos y egresos discriminados por rubros}

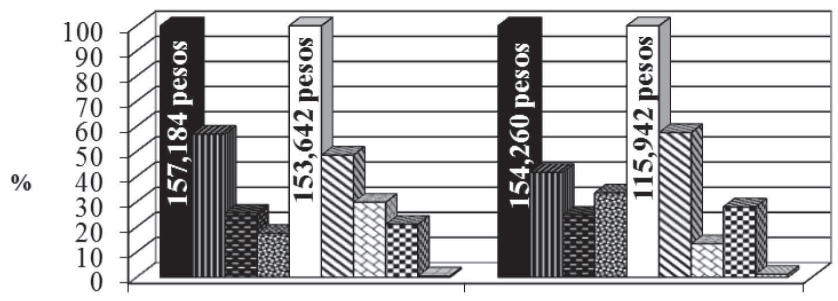

El Castaño

- Ingresos totales

- Ingresos por aportes gubernamentales $\square$ Egresos totales

r Otros gastos familiares

La Palma

m Ingresos productivos

Otros ingresos

■ Gastos para necesidades básicas

国astos productivos

Fuente: elaboración propia.

\section{Gráfica II}

\section{Niveles de financiamiento de las familias}

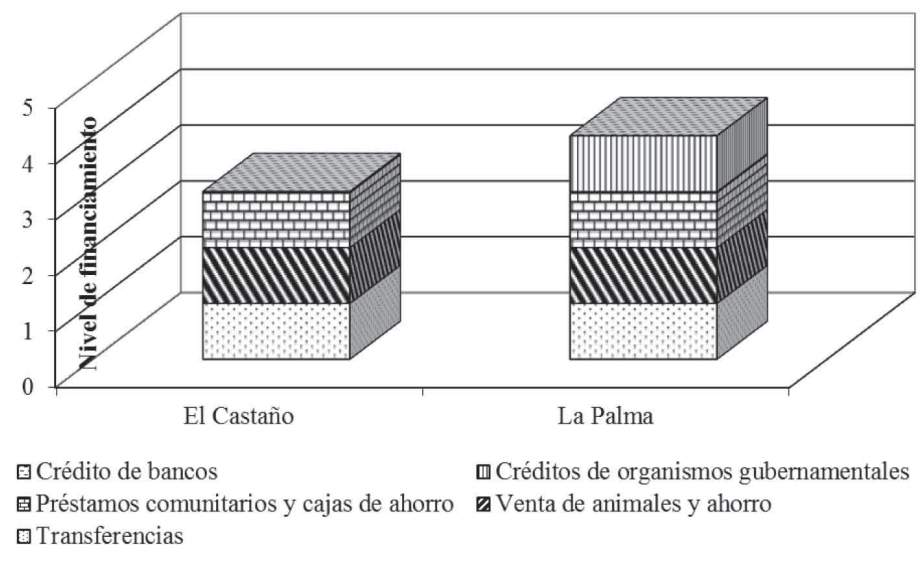

Fuente: Elaboración propia.

Del análisis del calendario anual de actividades (cuadro 3) se desprende que existen limitantes para poder organizar las actividades de manera ideal, considerando la actividad económica alternativa complementaria a la tradicional pesquera y asegurando así ingresos mensuales constantes para las familias. En el cuadro 3 se corrobora que los dos meses con mayor afluencia de turismo (abril y diciembre) se superponen con periodos de pesca buenos a regulares. 


\section{Cuadro 3}

\section{Calendario anual de actividades}

\begin{tabular}{clcccccccccccc}
\hline \multicolumn{1}{c}{ Meses } & Ene & Feb & Mar & Abr & May & Jun & Jul & Ago & Sep & Oct & Nov & Dic \\
\hline \multirow{5}{*}{ El Castańo } & Pesca & $\downarrow$ & $\downarrow$ & $\downarrow$ & $\downarrow$ & $\leftrightarrow$ & $\leftrightarrow$ & $\downarrow$ & $\downarrow$ & $\uparrow$ & $\uparrow$ & $\uparrow$ & $\uparrow$ \\
& Ecoturismo & $\leftrightarrow$ & $\downarrow$ & $\downarrow$ & $\downarrow$ & $\downarrow$ & $\downarrow$ & $\leftrightarrow$ & $\downarrow$ & $\downarrow$ & $\downarrow$ & $\downarrow$ & $\uparrow$ \\
& Lesca & $\downarrow$ & $\downarrow$ & $\leftrightarrow$ & $\downarrow$ & $\leftrightarrow$ & $\leftrightarrow$ & $\leftrightarrow$ & $\uparrow$ & $\leftrightarrow$ & $\uparrow$ & $\uparrow$ & $\uparrow$ \\
\multirow{5}{*}{ La Palma } & Ecoturismo & $\leftrightarrow$ & $\downarrow$ & $\downarrow$ & $\downarrow$ & $\downarrow$ & $\downarrow$ & $\leftrightarrow$ & $\downarrow$ & $\downarrow$ & $\downarrow$ & $\downarrow$ & $\uparrow$ \\
\hline
\end{tabular}

Referencias: $\uparrow$ bueno; $\leftrightarrow$ regular; $\downarrow$ malo; $\downarrow$ en Semana Santa aumento de precios en pesca y llegada de visitantes.

Fuente: Elaboración propia.

\subsubsection{Capital social}

Los sistemas sociales organizativos básicos son importantes para comprender el tipo de relaciones al interior comunitario. En EC lo constituye la familia extendida, estructurada en grupos económicos y formalizados a través de las dos cooperativas locales (pesquera y de ecoturismo). En LP las formas de agrupación son compatibles con la estructura extracomunitaria de gestión, donde responden a los criterios económicos (cooperativas de pesca, transporte y ecoturismo) o a los organizativos comunitarios (salud, educación e infraestructura). Sin embargo, de acuerdo con relatos de los habitantes de LP, en los inicios de la ranchería el sistema organizativo básico también se representó por un sistema de familia extendida.

En el ámbito institucional, es posible notar que la escala local se relaciona con múltiples niveles superiores (cuadro 4). En ambas rancherías se presentan interacciones externas en los ámbitos municipal, estatal y federal y, en el caso de las cooperativas de ecoturismo, también se presentan nexos con organizaciones internacionales. El principal criterio local de identificación de relaciones es el de prestación de programas o financiamiento de proyectos, situándose en segundo lugar las relaciones de servicio, entre las que se encuentran las insatisfechas, como los recurrentes reclamos a la Comisión Federal de Electricidad (CFE) para la restitución del servicio eléctrico en época de tormenta.

Cabe destacar que si bien la Secretaría de Turismo (Sectur) fue mencionada por los participantes del taller diagnóstico de LP como la principal reguladora de turismo y transporte, de acuerdo con los miembros de las cooperativas del sector esta institución aún no tiene presencia local. Los permisos serían canalizados a través de las autoridades de instituciones con jurisdicción ambiental. Sin embargo, ambas cooperativas de 


\section{Cuadro 4}

\section{Instituciones relacionadas a El Castaño (EC) y La Palma (LP)}

\begin{tabular}{|c|c|c|c|}
\hline Institución & Tipo de relación & Rancheria & Ámbito \\
\hline $\begin{array}{l}\text { Presidencia municipal (de } \\
\text { Acapetahua, MA; de } \\
\text { Mapastepec, MM) }\end{array}$ & $\begin{array}{l}\text { Financiamiento } \\
\text { Solicitudes de } \\
\text { servicios }\end{array}$ & LP; EC & Municipal \\
\hline $\begin{array}{l}\text { Iglesia católica de Mapastepec } \\
\text { (ICM) y Diócesis de Tapachula } \\
\text { (ICT) }\end{array}$ & $\begin{array}{l}\text { Formación religiosa } \\
\text { Conexiones } \\
\text { intercomunitarias }\end{array}$ & EC & $\begin{array}{l}\text { Municipal; } \\
\text { Regional }\end{array}$ \\
\hline $\begin{array}{l}\text { Organización no } \\
\text { gubernamental (oNG regional) }\end{array}$ & $\begin{array}{l}\text { Generación de } \\
\text { proyectos } \\
\text { Búsqueda de } \\
\text { financiamiento }\end{array}$ & LP & Regional \\
\hline $\begin{array}{l}\text { Secretaría de Pesca y } \\
\text { Acuacultura (Sepesca) }\end{array}$ & $\begin{array}{l}\text { Regulación pesquera } \\
\text { Financiamiento }\end{array}$ & LP; EC & Estatal \\
\hline $\begin{array}{l}\text { Universidad Autónoma de } \\
\text { Chiapas (UACH) }\end{array}$ & $\begin{array}{l}\text { Potencial-indirecta } \\
\text { Estudios de impacto } \\
\text { ambiental para } \\
\text { dragado de canal }\end{array}$ & EC & Estatal \\
\hline $\begin{array}{l}\text { Gobierno del Estado de } \\
\text { Chiapas (Chis.) }\end{array}$ & $\begin{array}{l}\text { Indirecta } \\
\text { Subsidios }\end{array}$ & LP & Estatal \\
\hline $\begin{array}{l}\text { Comisión Nacional de } \\
\text { Acuacultura y Pesca } \\
\text { (Conapesca) }\end{array}$ & $\begin{array}{l}\text { Regulación pesquera } \\
\text { Financiamiento }\end{array}$ & LP; EC & Federal \\
\hline $\begin{array}{l}\text { Comisión Federal de } \\
\text { Electricidad (CFE) }\end{array}$ & Servicio & LP; EC & Federal \\
\hline $\begin{array}{l}\text { Reserva de la Biosfera La } \\
\text { Encrucijada, Comisión } \\
\text { Nacional de Áreas Naturales } \\
\text { Protegidas (Rebien-Conanp) }\end{array}$ & $\begin{array}{l}\text { Capacitación } \\
\text { Financiamiento de } \\
\text { proyectos y } \\
\text { actividades }\end{array}$ & LP; EC & Federal \\
\hline $\begin{array}{l}\text { Procuraduría Federal de } \\
\text { Protección al Ambiente } \\
\text { (Profepa) }\end{array}$ & $\begin{array}{l}\text { Comités de Vigilancia } \\
\text { Participativos }\end{array}$ & EC & Federal \\
\hline Secretaría de Turismo (Sectur) & $\begin{array}{l}\text { Potencial } \\
\text { Regulación y apoyo al } \\
\text { sector turístico }\end{array}$ & EC; LP & Federal \\
\hline $\begin{array}{l}\text { Secretaría de Desarrollo Social } \\
\text { (Sedesol) }\end{array}$ & Subsidios & LP & Federal \\
\hline $\begin{array}{l}\text { Comisión Nacional para el } \\
\text { Desarrollo de los Pueblos } \\
\text { Indígenas (CDI) }\end{array}$ & $\begin{array}{l}\text { Financiamiento de } \\
\text { Proyectos }\end{array}$ & LP & Federal \\
\hline
\end{tabular}


Cuadro 4 (continuación)

\begin{tabular}{llll}
\hline \multicolumn{1}{c}{ Institución } & Tipo de relación & Ranchería & Ámbito \\
\hline Banco Mundial (BM) & $\begin{array}{l}\text { Indirecta } \\
\text { Financiamiento }\end{array}$ & EC & Internacional \\
$\begin{array}{l}\text { Organización no } \\
\text { gubernamental (ONG } \\
\text { internacional) }\end{array}$ & Apoyo financiero & EC; LP & Internacional \\
\hline
\end{tabular}

Fuente: Elaboración propia.

ecoturismo están procurando ingresar al padrón de servicios turísticos de Sectur, por lo que actualmente la relación es potencial.

En el análisis también se encontraron relaciones indirectas. Éstas representan financiamientos de una institución canalizados por medio de otra de índole local o regional, como sucede en EC, donde la cooperativa de ecoturismo ha recibido financiamiento del Banco Mundial por medio de la Rebien.

En el análisis de las redes sociales donde se incluyen las instituciones extra e intracomunitarias la densidad es medio-baja (valores de 0.1250 para EC y 0.1429 para LP; figura II). Ello implica que el número de relaciones existentes entre instituciones es muy inferior al esperado en teoría. $\mathrm{Al}$ excluir del análisis a las instituciones extracomunitarias, ambas rancherías elevan notablemente su valor de densidad, llegando a valores altos en EC $(\delta=0.45)$ y a regulares en LP $(\delta=0.2667)$.

\subsubsection{Capital humano}

El grado de marginación es alto (nivel de marginación: LP: -0,015; EC: $-0,515)$ en las dos rancherías. Ello indica la existencia de dificultades que enfrentan las familias en su día a día, sin embargo, se deben analizar las principales limitaciones desde la perspectiva de la población.

En relación con la educación, el porcentaje de alfabetismo es alto (capacidad de leer y escribir; LP $87.7 \%$ y EC $80 \%$ ), al igual que la inserción escolar de la población en edad de escolaridad obligatoria (6 a 14 años LP $94.7 \%$ y Ec $100 \%$ ), mientras que el grado promedio de escolaridad se corresponde con el de primaria incompleta (LP: 5.75 y EC: 4.09). En ambas rancherías existe escuela primaria y sólo en LP secundaria, sin embargo, es en la segunda ranchería donde existe disconformidad respecto a la calidad educativa local en referencia con la relación maestro/ alumno y la irregularidad de las clases. Las instancias de capacitación (educación informal) son discontinuas, destinadas a ciertos grupos productivos o comunitarios (sectorizada), donde las temáticas que se abordan generalmente las proponen las instituciones promotoras. 


\section{Figura II}

Redes sociales en El Castaño (superior) y La Palma (inferior)
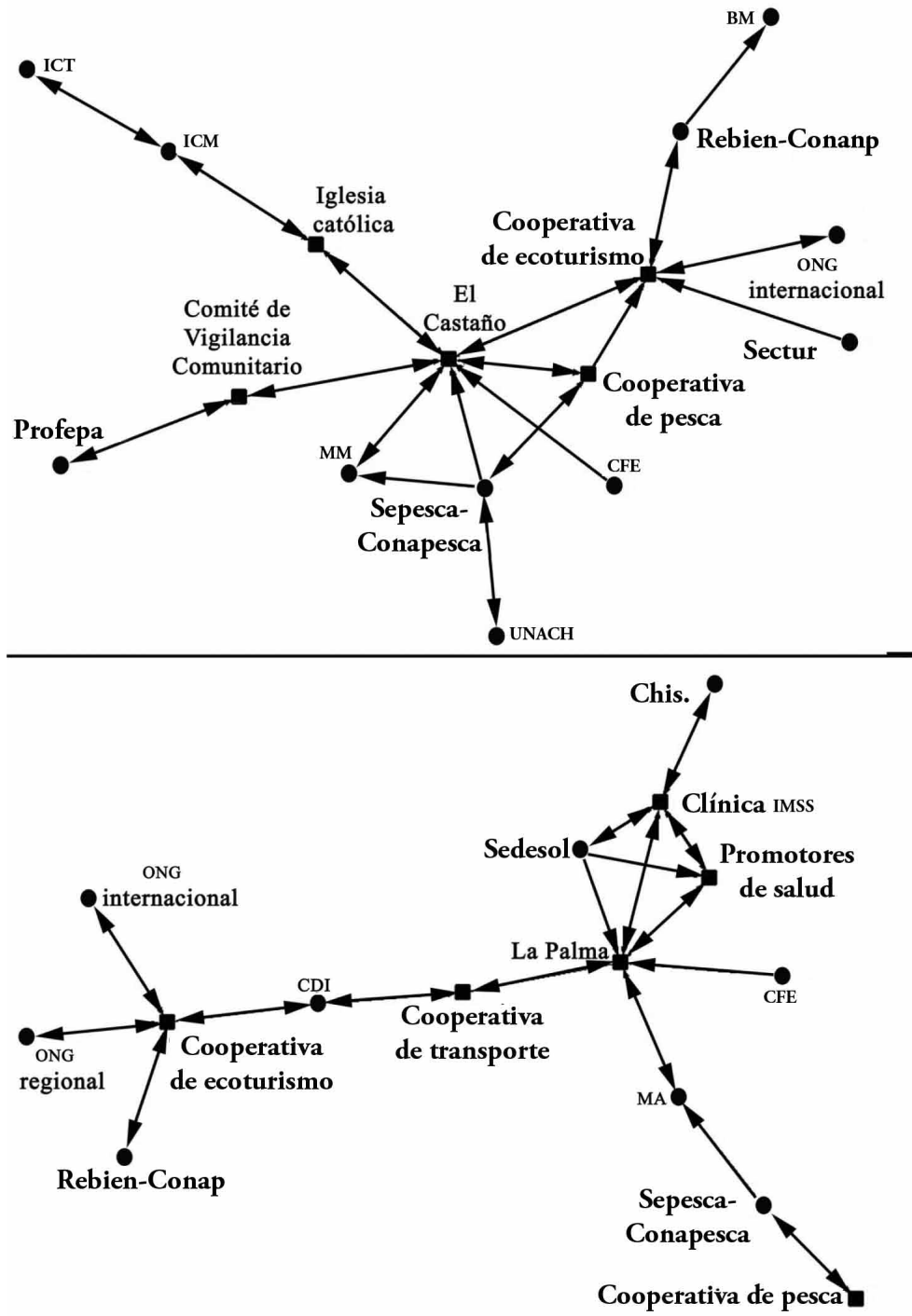

Nota: se indica en cuadros las instituciones locales y en círculos las extracomunitarias. Fuente: Elaboración propia. 
Finalmente, según el último conteo poblacional de 2005, el derecho al servicio de salud se considera bajo (LP: $10.5 \%$ y EC: $0 \%$ ). Durante el taller, los participantes expresaron que en la actualidad la mayoría de la población cuenta con Seguro Popular, aunque no ha sido eficaz, ya que localmente en el caso de EC no hay médicos permanentes y en LP no se pueden hacer estudios clínicos y las medicinas son escasas, por lo que los enfermos deben atenderse en las cabeceras municipales, y en caso de urgencias deben recurrir a médicos privados.

\subsubsection{Comparación de capitales entre comunidades}

La valoración de los capitales permite definir las áreas prioritarias de atención para planificar las prioridades de acción (gráfica III). Se consideran los capitales humano (salud y educación), social (necesidad de aumentar relaciones en las redes sociales) y físico (destacando los servicios de baja calidad o discontinuos) como prioritarios. En segundo término, se destaca la importancia de considerar las alteraciones ambientales, ya que ellas a su vez afectan directamente la economía familiar y se ha visto que no pueden ser resueltas con un nivel de incidencia local. Por último, si bien el capital financiero representa el recurso de mayor fortaleza, el análisis precedente demuestra que sigue siendo inestable e inseguro para las familias.

\subsection{Vulnerabilidad, estructuras, procesos, politicas y estrategias}

Se pudo observar que las familias de las rancherías bajo estudio son altamente dependientes de los recursos naturales, cuyo uso está restringido por regulaciones de instituciones externas y por el deterioro de la calidad y abundancia de los productos pesqueros. Dos factores son esenciales al momento de analizar el deterioro del sistema económico pesquero: por un lado la degradación ambiental, antes expuesta, y por el otro el mercado (como causa de impacto directo e indirecto). El mercado define los precios: en épocas de mayor pesca el valor comercial es menor y en los de menor pesca es mayor, regulando así la actividad económica y limitando las posibilidades de crear localmente estrategias que permitan a las familias lograr su bienestar. Por otro lado, el mercado también exige alta productividad, lo cual ha llevado a grandes modificaciones en la cuenca alta de los cursos de agua dulce, donde se han destinado las tierras a la agricultura y ganadería, cuyas alteraciones ambientales favorecen el azolvamiento en la cuenca baja y consecuentemente empeora la calidad del ambiente para el desarrollo del producto pesquero. 


\section{Gráfica III \\ Polígono comparativo de la valoración de los capitales con que cuentan las familias de EC $y$ LP}

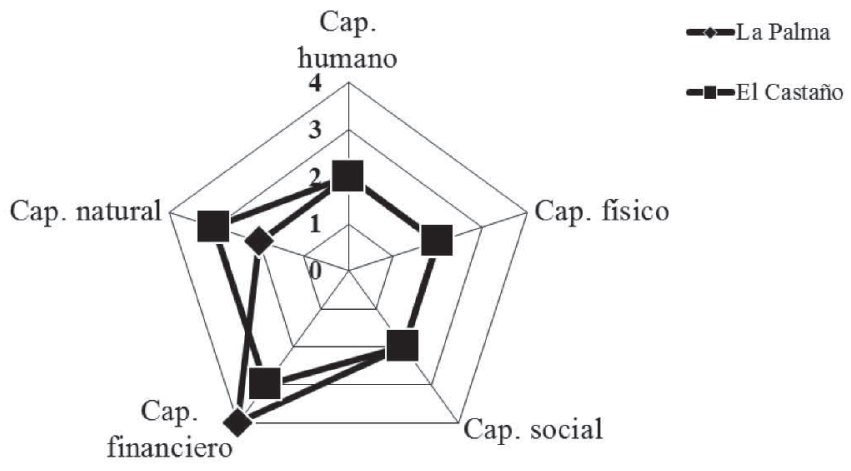

Nota: Escala de valoración: 0 no aplica; 1 muy malo; 2 malo; 3 regular; 4 bueno; 5 muy bueno (no necesariamente óptimo).

Fuente: Elaboración propia.

Por otro lado, es notorio que en ambas rancherías reconocen los eventos climáticos como sucesos relevantes dado su poder destructivo. Los huracanes más destacados fueron los que afectaron la zona en 1998 y 2005. El impacto de los mismos se definió por las inundaciones sufridas, el aislamiento, el incremento de enfermedades, la afectación a los manglares, las pérdidas casi completas en hogares, y en EC también la pérdida de los cultivos y el ganado. Hasta la restitución de los niveles normales de agua la gente buscó otras formas de generar ingresos (por ejemplo, jornalero), para luego proseguir con la pesca. A pesar de las condiciones desfavorables, el alimento nunca faltó porque siempre hubo peces para pescar, además de las contribuciones recibidas por algunas instituciones. Así, la pesca se constituye como un factor de seguridad alimentaria que connota un sentimiento de pertenencia al territorio.

La escasez de oportunidades de trabajo para la gente joven los lleva a migrar. En este contexto, el significado que cobra la migración (en los jóvenes y algunos adultos) es revelador de la pertenencia al territorio, pero se opta por ella ante el deterioro pesquero y se ve como una oportunidad para complementar el ingreso familiar o para ahorrar e invertir al regreso, principalmente en casas y cayucos. Así, en la mayoría de los casos las expectativas están puestas en retornar a su tierra. 
Las estrategias económicas familiares consisten en la combinación de actividades que lleva a cabo una familia para sobrevivir el día a día. Al interior de las familias se desarrollan diversas actividades, lo cual los lleva a desempeñarse de manera eficiente realizando una división del trabajo. Dadas las dificultades para poder afrontar la subsistencia familiar con base en la actividad tradicional local (la pesca), se han incorporado otros sistemas de ingreso para compensar la inestabilidad de su principal sistema económico. Sin embargo, las estrategias familiares se siguen caracterizando por una baja diversificación, con centralidad en la pesca y generando emprendimientos familiares, como la cría de animales y en EC también el cultivo de maíz para autoabasto, complementando sus ingresos con aportes gubernamentales provisorios y una búsqueda de alternativas fuera del ámbito local (migración).

El ecoturismo aún no se ha incorporado en la estrategia productiva familiar comunitaria. Por un lado, porque esta alternativa económica no involucra a la totalidad de los habitantes de las rancherías, por lo que no se reconoce como una de las actividades prioritarias. Por otro lado, las familias involucradas aún no reciben beneficios directos y permanentes, ya que los escasos ingresos los utilizan sobre todo para afrontar gastos y mantenimiento.

Si bien el ecoturismo no se presenta como un elemento de la estrategia económica familiar, éste es parte de los componentes que involucran el cambio de uso del territorio a nivel histórico (figura III). Tradicionalmente la pesca ha sido el recurso más representativo, ya sea para el autoabasto o la comercialización. La agricultura y la ganadería representan actividades realizadas de tiempo atrás, pero que se han ido abandonando por diferentes causas, como la carencia de tierra (LP), o la dificultad ante plagas e inestabilidad de los precios de mercado (EC).

En EC, la percepción de la gente presenta al ecoturismo como una actividad que se desprende del grupo pescador central de la comunidad (figura III). Ello remite a la organización social básica, donde las relaciones de parentesco son las predominantes, por lo que el surgimiento de una nueva alternativa está conectada y en sintonía con las otras actividades.

En LP se percibe la aparición del ecoturismo como un aspecto aislado de las restantes actividades locales (figura III). A diferencia de ello, es trascendente considerar que los cambios históricos de uso del territorio se perciben relacionados, así, se presenta un énfasis creciente en la pesca $\mathrm{y}$ un abandono paulatino de diversas actividades económicas. 


\section{Figura III}

Cambio histórico del uso del territorio en El Castaño (izquierda) y La Palma (derecha)

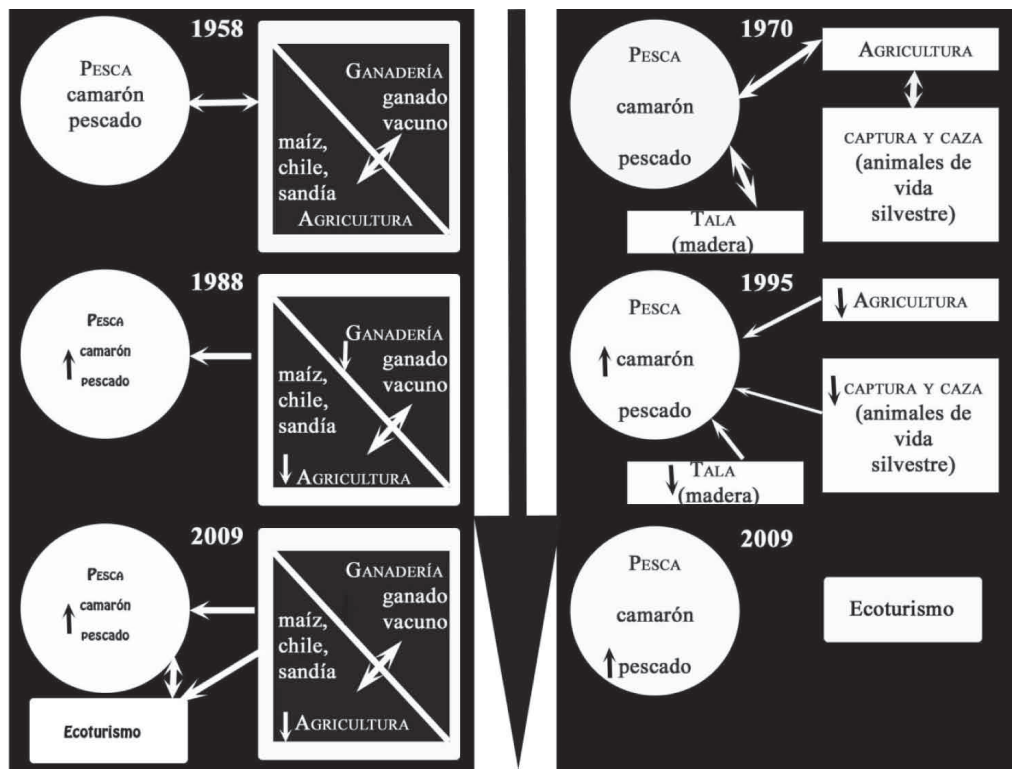

Referencias: las flechas indican las relaciones entre actividades ( $\leftrightarrow$ combinación; $\downarrow$ transición) y el estado de cada actividad en cada periodo ( $\downarrow$ disminución; $\uparrow$ aumento).

Fuente: Elaboración propia.

\section{Ecoturismo y ruralidad: ¿oportunidad, desafío o paliativo?}

Como primera medida de una planificación es necesario reconocer en el territorio con qué recursos, oportunidades y limitantes cuentan la gente, las familias y las comunidades e identificar sus necesidades de cambio y sus perspectivas a futuro. Ello fundamentado desde la postura de Chambers (1995), según la cual las medidas que pueden hacer la diferencia para la gente pobre es posible que, sin embargo, estén basadas en un bajo costo de financiamiento.

En el análisis integral comparativo de los capitales de los medios de vida es posible observar una alta uniformidad en los datos, a pesar de las diferencias reportadas entre ambas rancherías. Diversos aspectos resultan de la reflexión de la información obtenida: 1) existen diferencias en las posibilidades de educación formal, atención de salud, infraestructura y servicios entre las dos rancherías, sin embargo, el énfasis puesto desde las políticas en los aspectos de infraestructura más que en los funcionales, hacen que en LP, donde se observa una mejor situación, los habitantes se 
muestran disconformes, por lo que al incluir la percepción local se obtienen resultados similares; 2) las relaciones formales en el ámbito local están fuertemente influidas por la estructura macro, con lo cual se tiende a una fragmentación que conlleva a la pérdida de objetivos en común; 3) se presenta una conducta proactiva diferente entre los actores sociales relevantes de cada ranchería, pero las estructuras administrativas y burocráticas homogenizan los procesos; 4) las diferencias en las posibilidades de financiamiento resultan en más oportunidades para sobrellevar las carencias de las familias, en vez de la posibilidad para generar inversiones duraderas; 5) el deterioro ambiental incide directamente en la economía familiar centrada en la pesca; 6) las causas del deterioro ambiental requieren políticas integrales en los aspectos espacial e institucional, y 7) las iniciativas locales son opacadas ante la falta de apoyo institucional, cuando no es financiamiento económico lo que está en juego.

El hecho de incorporar el componente ambiental en una alternativa de desarrollo no asegura la protección de los recursos naturales (Bringas y González, 2004). Algunos recursos naturales básicos del ámbito rural, como el agua y la leña, deben ser factores foco de atención. Se ha observado que la creciente demanda de agua en los sectores turísticos pone en riesgo la capacidad de provisión y su calidad (Vera, 2006), a la vez que el incremento abrupto en la recolección de leña para alimentar fogones puede causar daño ambiental (Epler, 1998) y desabastecer a las familias de este recurso para su autoabasto. Estos son factores que aún no afectan a las comunidades implicadas en este estudio, dada la baja afluencia actual de turistas. Sin embargo, un interés permanente de las autoridades de la Rebien es lograr que otros emprendimientos regionales de turismo convencional incluyan una tipología más sustentable para evitar problemas ambientales.

Numerosas alteraciones han sido documentadas para el sistema de manglar en el que se encuentran ambas rancherías (Tovilla, 2007). La mayoría de ellas accidentales (como incendios) o motivadas por la deforestación para destinar las tierras a actividades productivas (agricultura, ganadería, canalización, dragado o bordeado de pampas) y por la implementación de infraestructura (construcción de carreteras y rectificación de cursos de agua dulce). Todos los eventos y procesos mencionados han afectado, y lo siguen haciendo, el sistema de manglar predominante en la zona, del cual depende la economía pesquera y de cuyo atractivo ha empezado a depender la prosperidad del sector turístico.

Los antecedentes indican que el ecoturismo raramente contribuye a mejorar el capital físico destinado a aumentar las comodidades de los habitantes locales (McLaren, 1998), lo que coincide con los datos de este estudio. En la Selva Lacandona (Chiapas) se reportó que la infraestruc- 
tura de servicios de las comunidades donde se implementan proyectos de ecoturismo es precaria, considerando escuelas, calles, agua potable, electrificación y servicios de salud (Reygadas et al., 2006). Sumado a ello, el ecoturismo debería requerir bajos costos de inversión en infraestructura como ventaja comparativa con el turismo en masas (Bringas y Ojeda, 2000), sin embargo, las condiciones de precariedad de las áreas rurales y su marginalidad incrementan los costos para lograr las mínimas condiciones necesarias.

El entorno económico no puede ser excluido en el desarrollo de la actividad turística (Magaña, 2009). Uno de los factores limitantes destacados para las pesquerías es el mercado. Éste es representativo de la inequidad de poder y se manifiesta en la incapacidad de elección, por tanto, en una carencia de libertad (Evans, 2002). Es en este punto que surge la pregunta: ¿puede el ecoturismo desarrollarse óptimamente ante un creciente deterioro ambiental y presiones de un nuevo mercado? Pregunta que ya ha sido parcialmente respondida: el mercado turístico requiere de altas inversiones (Ferreira, 2005; Reygadas et al., 2006) y deja los menores beneficios a nivel local (López y Palomino, 2008; Bringas y Ojeda, 2000; Skoczek, 2003), lo cual promueve una dependencia a subsidios o apoyos. Así, la introducción del ecoturismo como actividad económica plantea un gran desafío: un cambio del ser, hacer y nuevas relaciones de mercado característicamente inequitativas.

Las preferencias de la gente en relación con los bienes y los resultados exceden el plano económico (Evans, 2002), sin embargo, en el caso analizado son esenciales a la hora de caracterizar la economía local. La pesca envuelve el ser y saber hacer, los pobladores son pescadores con sus habilidades desarrolladas, el cambio de actividad económica implica no sólo aprender a hacer, sino además cambiar su relación hombre-naturaleza. Se ha reportado que el cambio de la cultura pesquera a la del turismo se da como respuesta a una búsqueda de progreso económico (Pastor, 2003) que, sin embargo, lleva a una dependencia económica (Moreno, 2005).

Sumado a lo anterior, el ecoturismo debería actuar como una actividad complementaria a las que se desempeñan localmente (Ross y Wall, 1999: 129), procurando una estrategia pluriactiva de las familias (Oliveira y González, 2008). Sin embargo, considerando que esta actividad no intenta superar las causas que llevan a las familias a buscar nuevas alternativas (alteraciones ambientales que llevan a una disminución del producto pesquero), si no atiende las consecuencias (ingresos insuficientes de las familias) y sólo de un sector minoritario, las tendencias indican una predisposición a adoptar esta actividad como suplementaria. Al reconocer esta tendencia, es necesario destacar que la temporalidad del trabajo turístico ha sido documentada en otros casos en Chiapas, donde los más afectados econó- 
micamente son los miembros que no tienen posibilidades de recibir otros ingresos (Hernández et al., 2005), por lo que la desigualdad social se incrementa.

Considerando que el ecoturismo sólo estaría dirigido a mejorar los ingresos de las familias y no a revertir las causas del deterioro ambiental, se contradice con los objetivos planteados por la Conanp donde se propone "el desafío de detener el deterioro de los ecosistemas y su biodiversidad, así como mitigar las condiciones de pobreza y marginación de las comunidades involucradas, para situarlas en un horizonte de desarrollo sustentable local", y de acuerdo con esto se propone propiciar el ecoturismo (Conanp, 2007).

El aumento descrito en este estudio en la densidad de las redes sociales al excluir las instituciones externas podría interpretarse como efecto de excluir nexos, sin embargo, al observar las redes es posible notar que las instituciones extracomunitarias carecen de relaciones entre sí y apoyan sólo a ciertos grupos o sectores comunitarios, por lo que estarían contribuyendo por medio de sus mecanismos de gestión a la fragmentación social. Según la teoría de Mary Douglas (Milton, 1996), la constitución y formalización de grupos se puede interpretar desde el punto de vista social como un mecanismo de sectorización, mientras que la cohesión se representa sobre todo por la existencia de redes. Así, es posible notar que la fragmentación reconocida en las políticas globales repercuten en la escala local por medio de la asimilación de esos modelos de organización.

En relación con el ecoturismo, otros autores han enfatizado en el proceso de sectorización social, en alusión a los grupos que lo implementan (Li y Han, 2000; Ferreira, 2005; Schärer, 2003; Reygadas et al., 2006), y en lo que toca a dichos procesos se ha visto que generan exclusión en la toma de decisiones y beneficios diferenciales (Jones, 2005; Reygadas et al., 2006), así que en lugar de disminuir las diferencias socioeconómicas puede aumentarlas e incluso es posible que se desencadenen conflictos al interior de las comunidades, ante la desarticulación de los sistemas organizativos sociales básicos dada por la incorporación de una nueva actividad económica (Hernández et al., 2005). Sin embargo, los datos presentados en el ámbito comunitario estarían indicando que esta sectorización surge como respuesta a la estructura macro, más que a una predisposición interna de los grupos, lo cual lleva a mayores dependencias hacia el exterior que hacia el interior de la escala local. Estos hechos se consideran problemáticos para el proceso de construcción territorial, entre los que se destacan "el enfrentamiento entre políticas sectoriales y territoriales; estructuras centralizadas y descentralizadas, tanto de gestión como de planeación: ambiente institucional local y externo, entre los más relevantes" (Flores, 2007: 35). 
El análisis del capital humano, en general, se restringe a las cualidades para el desarrollo económico, enfatizando en la agencia de los actores, sin embargo, es necesario ampliar esta concepción a las capacidades humanas que posibilitan la elección de la vida que se quiere vivir en función de los propios valores, siendo a la vez instrumento del crecimiento económico y el desarrollo social, donde la salud y la educación son vectores que permiten manejar las propias vidas y elegir cómo hacerlo (Sen, 1997), a la vez que posibilitan disminuir el estado de riesgo (Sen, 2002). Partiendo de esta concepción, esencialmente las políticas pueden usar dos mecanismos. El primero (growth-mediated) depende del crecimiento económico para poder generar servicios (salud, educación y seguridad), mientras que el segundo (support-led) enfatiza en programas destinados a dar un soporte social a través del desarrollo de capacidades (Sen, 1999). En este estudio se puede observar que las políticas se centran en el primer mecanismo, altamente dependiente de inversiones económicas, mientras que el segundo, el cual podría fomentar construcciones más duraderas y posibilitar mayor libertad y elección, no se aborda. Se presentan medidas utilitarias en todos los ámbitos (salud, educación, producción), donde se apoyan o realizan obras de infraestructura, se otorgan subsidios o aportes y no se ahonda en la reflexión y la construcción de capacidades para afrontar los problemas desde adentro y conjuntamente.

La expansión de las capacidades de la gente depende tanto de la provisión de facilidades para educación básica, cuidado de la salud y redes de seguridad social como de la eliminación de la opresión, lo cual debe pensarse en términos de acciones colectivas, tendientes a formular valores y preferencias propios e instrumentos para darles soporte, donde los significados de la acción colectiva (como identidad, valores y objetivos) son esenciales para la libertad (Evans, 2002) y las configuraciones sociales para generar mecanismos de seguridad (Sen, 2002). Esa necesidad de acción colectiva fortalecedora de construcciones en torno de la seguridad es limitada al reforzarse la sectorización social.

A partir de los datos anteriores surge la pregunta de si el ecoturismo está actuando o podría convertirse en una alternativa que propicie el desarrollo local basado en las particularidades del territorio. Para dar respuesta a ello debemos considerar que

se transita hacia el desarrollo local cuando se presentan proyectos derivados de iniciativas de la comunidad, cuando su organización y adecuación en términos técnicos y prácticos le dan factibilidad a tales iniciativas y permiten a la población local mejorar sus condiciones de vida, y cuando incluyen premisas como la amplia y activa participación de la población en el rescate de los niveles productivos necesarios y la identificación de los recursos disponibles para que se utilicen de manera más eficaz (Serrano, 2008: 336). 
"Las experiencias exitosas de desarrollo sustentable y las mejoras en torno a la calidad de vida y al ambiente han resultado ser más la excepción que la regla" (Bringas y González, 2004: 552). Una vez identificadas las numerosas dificultades que enfrentan los grupos y considerando que el ecoturismo ha sido y se sigue promocionando desde diversas instituciones gubernamentales y no gubernamentales, es preciso reconocer que "debería ser claro que no existen grandes alternativas que puedan aplicarse a todos los lugares y todas las situaciones" (Escobar, 1996: 416). Además, se destaca que no es suficiente el potencial natural o cultural sin la valoración social (Bringas y González, 2004) y que es imprescindible considerar las características propias de cada lugar en pos de la efectividad (Magaña, 2009). A pesar de las limitaciones descritas, la fortaleza de los emprendedores locales les ha permitido lograr numerosos avances como respuesta a su iniciativa de sacar adelante sus proyectos, siendo su principal sustento el arraigo a su territorio y la falta de herramientas para resolver las causas del deterioro pesquero.

\section{Conclusiones}

$\mathrm{Al}$ asumir el segundo modelo de la relación turismo rural-ecoturismo, se destacó como base la concepción de ruralidad. Este modelo más allá del aporte teórico implica la necesidad de reconocer que el área donde se desarrolla el turismo posee limitaciones que deben ser consideradas, las cuales se pusieron de manifiesto durante los talleres participativos con base en medios de vida.

La metodología de medios de vida permitió un enfoque multidimensional de la realidad de las comunidades con una perspectiva en la que éstas se desarrollan en el día a día. Desde esta postura, fue posible construir la estrategia, integrando y relacionando las actividades constitutivas desde su visión, identificando además los factores que llevan a esa combinación particular. Sobre todo, permitió definir las limitantes que podrían afectar el desarrollo del ecoturismo (de importancia a nivel propositivo), así como el papel que tiene esta actividad en las rancherías considerando la complejidad local.

En el caso estudiado, las características comunitarias, sus problemas y deficiencias son representativos de un sistema rural con particularidades que deben ser reconocidas. La opresión principal está dada por la falta de medidas integrales para resolver los problemas desde sus causas e involucrando a los diversos actores locales y por la falta de medidas que apoyen o fomenten la construcción de capacidades que permitan buscar las soluciones más adecuadas y propicien espacios sociales destinados a ello. Los mecanismos implementados promueven un régimen de dependencia, 
donde las instituciones son responsables y los habitantes se acomodan a un sistema ineficiente para ellos.

Las políticas (en educación, salud, productivas) se caracterizan por ser utilitarias, lo cual requiere altos costos de inversión y mantenimiento. No se consideran otras posibilidades como la creación de programas que tiendan a fortalecer las capacidades y con ello fomentar la libertad y la elección, y a su vez, apoyar la constitución de redes internas. Este último mecanismo se considera esencial pensando en las dificultades y el aislamiento que se enfrenta en el área rural. Desde esta perspectiva, el desarrollo territorial no puede concebirse separado de la construcción territorial.

Para los habitantes locales la creación del ANP no ha significado un factor que propiciara un mejor estado de su ambiente o una mejor calidad de vida, contrario a los objetivos de la Conanp. Las principales causas del deterioro ambiental están fuera del ámbito de acción de las comunidades y de la jurisdicción de la ANP, lo cual se agrava por la falta de coordinación entre las instituciones responsables de los diversos sectores (social, conservación, productivos, etc.) para llevar a cabo acciones conjuntas e integrales en el ámbito regional.

Las políticas ambientales favorecen a las familias porque promueven un equilibrio del medio natural, del cual depende su principal sistema económico. Sin embargo, estas políticas no responden de manera integral a las necesidades locales ni involucran a las poblaciones en su formulación, por lo que se perciben como medidas coercitivas que limitan la libertad y ponen en riesgo la seguridad de subsistencia familiar al restringir el acceso y uso de los recursos naturales. Se intenta superar esas restricciones promoviendo nuevas actividades compatibles con las políticas ambientales, pero no necesariamente con las potencialidades o medios de vida locales, como lo es el ecoturismo. Potencialidades que no sólo implican el poder hacer, sino además superar las dificultades que el mismo ámbito rural representa con escasez o falta de servicios de salud adecuados, servicios de agua y energía poco apropiados, aislamiento que no sólo dificulta la movilidad sino también la promoción y difusión de los emprendimientos.

Como parte de esas políticas, el ecoturismo se ha desarrollado con más infraestructura pero sin generar mejoría en el bienestar de todas las familias. Tampoco aporta soluciones a las economías tradicionales, sustento de los medios de vida locales, aunque evita la incorporación de nuevas actividades dependientes del uso directo de los recursos naturales, las cuales se encuentran restringidas por las políticas de conservación. Sumado a ello, los emprendedores de esta alternativa económica deben enfrentar nuevas dificultades, como aprender los nuevos saberes del ser y hacer y, sobre todo, lidiar con un mercado desconocido e igualmente inequita- 
tivo, como el ya conocido mercado pesquero. Finalmente, el principal aporte del ecoturismo ha sido generar esperanzas y expectativas de un futuro mejor, lo cual es el motor de trabajo de quienes se desempeñan en este ámbito, aportando horas de esfuerzo y dedicación para llegar algún día a compartir su lugar con el mundo.

\section{Agradecimientos}

Queremos agradecer a las autoridades, población y cooperativas de ecoturismo de El Castańo y La Palma, cuyo conocimiento y disposición hizo posible la realización de este estudio. A los coautores del Manual de Planeación Comunitaria, y a los facilitadores y cofacilitadores de los talleres. 


\section{Anexo I}

\section{Sistematización general para valorar los capitales}

\begin{tabular}{|c|c|c|c|}
\hline Categoría & Variable & Escala & Valoración \\
\hline $\begin{array}{l}\text { Capital } \\
\text { natural }\end{array}$ & $\begin{array}{l}\text { Efecto del uso } \\
\text { del territorio } \\
\text { Acceso a los } \\
\text { recursos } \\
\text { naturales } \\
\text { Dependencia } \\
\text { económica de } \\
\text { los recursos } \\
\text { naturales }\end{array}$ & $\begin{array}{l}\text { Modificación o } \\
\text { alteración de cada } \\
\text { variable: } \\
\text { 1. Alteración alta } \\
\text { 2. Alteración media } \\
\text { 3. Alteración baja } \\
\text { 1. Externa y local } \\
\text { 2. Externa } \\
\text { 3. Ausente } \\
\text { 1. Degradación } \\
\text { 2. Restauración } \\
\text { 3. Se mantiene } \\
\text { equilibrio } \\
\text { 1. Prohibido } \\
\text { 2. Restringido } \\
\text { 3. Regulado } \\
\text { 1. Alta } \\
\text { 2. Media } \\
\text { 3. Baja }\end{array}$ & $\begin{array}{l}\text { Los valores de agua, } \\
\text { suelo, flora, fauna y aire } \\
\text { se promedian. La suma } \\
\text { de este valor y de las } \\
\text { restantes categorías dan } \\
\text { valor al capital: } \\
1=\geq 5-6 \\
2=\geq 7-8 \\
3=\geq 9-11 \\
4=\geq 12-13 \\
5=\geq 14-15\end{array}$ \\
\hline Capital físico & $\begin{array}{l}\text { Agua } \\
\text { Sistema de } \\
\text { desecho de aguas } \\
\text { residuales } \\
\text { Energía } \\
\text { Educación } \\
\text { Salud } \\
\text { Vías de } \\
\text { comunicación } \\
\text { interlocales } \\
\text { Herramientas } \\
\text { productivas }\end{array}$ & $\begin{array}{l}\text { Evaluación externa: } \\
\text { los criterios para } \\
\text { cada categoría } \\
\text { fueron } \\
\text { disponibilidad, } \\
\text { tipología, calidad y } \\
\text { cobertura. Cada } \\
\text { criterio se evaluó } \\
\text { según una escala del } \\
1 \text { al } 3 . \text { Los resultados } \\
\text { para cada categoría } \\
\text { se convierten en: } \\
\text { Malo = <2- } \leq 4 \\
\text { Regular = >4- } \leq 9 \\
\text { Bueno = >9-12 } \\
\text { Evaluación interna: } \\
\text { los participantes } \\
\text { evalúan como buena } \\
\text { y/o mala a cada } \\
\text { categoría }\end{array}$ & $\begin{array}{l}\text { La valoración responde } \\
\text { a: } \\
1 \text { = no hay categorías en } \\
\text { los campos de bienestar } \\
\text { o adaptación } \\
2 \text { = menos de } 50 \% \text { de las } \\
\text { categorías analizadas } \\
\text { corresponden a bienestar } \\
\text { y adaptación } \\
3=\text { más de } 50 \% \text { de las } \\
\text { categorías analizadas } \\
\text { corresponden a bienestar } \\
\text { y adaptación } \\
4=\text { más de } 75 \% \text { de las } \\
\text { categorías analizadas } \\
\text { corresponden a bienestar } \\
\text { y adaptación } \\
5 \text { = más de } 50 \% \text { de las } \\
\text { categorías analizadas } \\
\text { corresponden a bienestar }\end{array}$ \\
\hline
\end{tabular}


continua Anexo i...

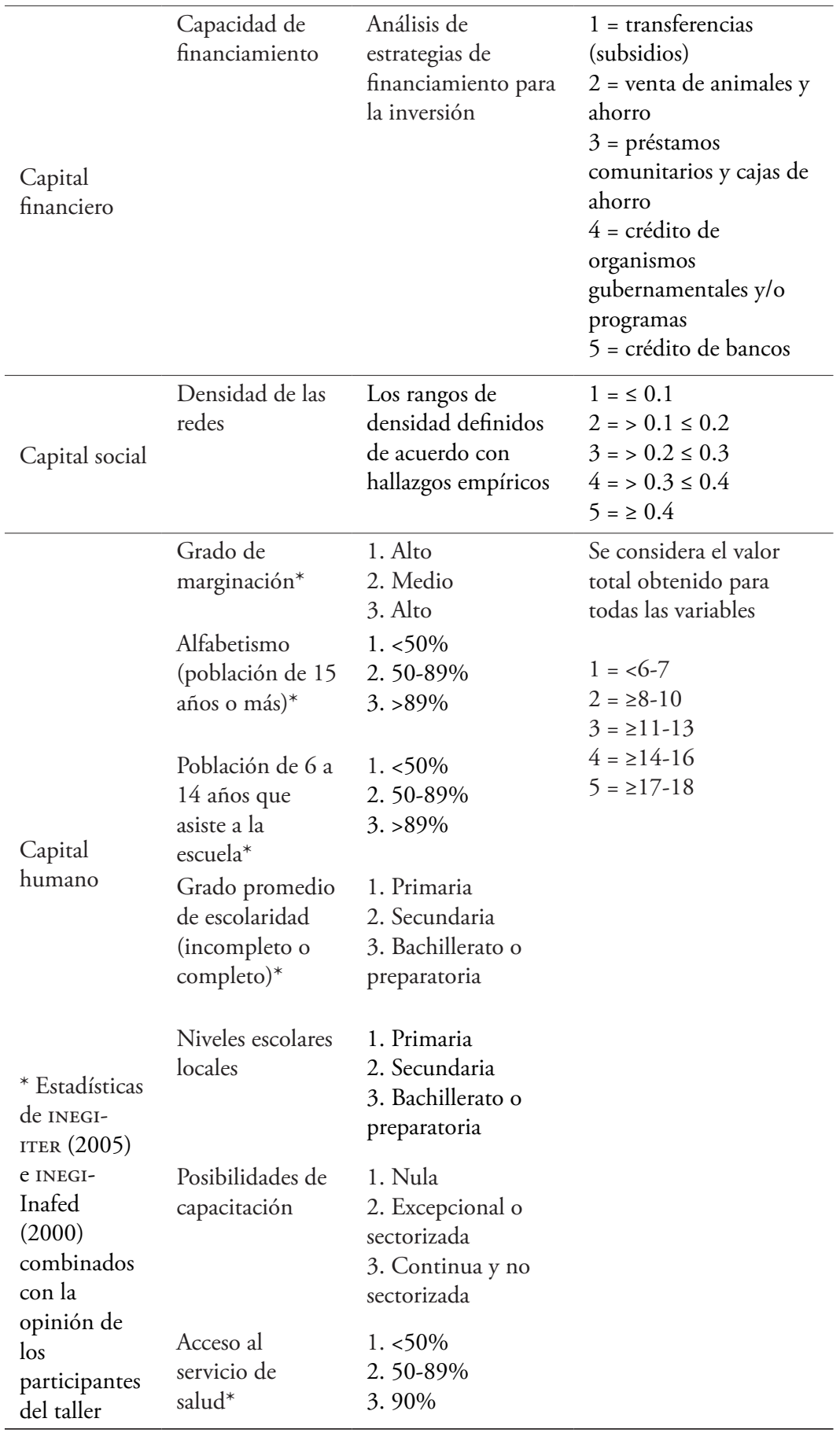

Fuente: Elaboración propia. 


\section{Bibliografía}

Arce-Ibarra, Ana Minerva y Alberto Isaac Gastelú-Martínez (2007), "Linking social and natural sciences methods using Mind Maps: A case study of human-nature interactions in Mexico's Lowland Maya area", The International Journal of Interdisciplinary Social Sciences, 2, Universidad de Illinois, Champaign, pp. 39-52.

Arce-Ibarra, Ana Minerva y Anthony Charles (2008), "Inland fisheries of the Mayan Zone in Quintana Roo: Using a combined approach to fishery assessment for data-sparse fisheries", Fisheries Research, 91, Elsevier, Amsterdam, pp. 151-159.

Arriaga-Cabrera, Laura, José Manuel Espinoza Rodríguez, Claudia Aguilar Zúñiga, Eduardo Martínez Romero, Leticia Gómez Mendoza y Eleazar Loa Loza (coords.) (2000), Regiones terrestres prioritarias de México, Comisión Nacional para el Conocimiento y Uso de la Biodiversidad, México, <http://www.conabio.gob.mx/conocimiento/regionalizacion/doctos/terrestres.html>, 23 de agosto de 2009.

Ashley, Caroline y Simon Maxwell (2002), "Rethinking rural development”, ODI Briefing Paper, marzo, Londres, pp. 1-4.

Batista-Foguet, Joan Manuel, Josep María Blanch y Maite Artés (1994), "Actitudes y calidad de vida", en Mariano Álvaro Page (coord.), Propuesta de un sistema de indicadores sociales de igualdad entre los géneros, Ministerio de Asuntos Sociales-Instituto de la Mujer, Madrid, pp. 311-374.

Bojnec, Štefan (2006), “Tourism development in Rural Areas”, Österreichische Gesellschaft für Agrarökonomie, Tagungsband, pp. 79-80, <http://oega.boku.ac.at/fileadmin/user_upload/Tagung/2006/ 06_Bojnec_tourism.pdf>, 25 de agosto de 2009.

Bringas-Rábago, Nora Leticia y Lina Ojeda Revah (2000), "El ecoturismo, ¿̨una nueva modalidad de turismo de masas?", Economía, Sociedad y Territorio, 2 (7), El Colegio Mexiquense, Zinacantepec, pp. 373-403.

Bringas-Rábago, Nora Leticia y J. Igor González A. (2004), "El turismo alternativo: una opción para el desarrollo local en dos comunidades 
indígenas de Baja California”, Economía, Sociedad y Territorio, 4 (15), El Colegio Mexiquense, Zinacanatepec, pp. 551-588.

Burgueño, Susana Pilar (2005), "Análisis de la actividad turística en áreas Naturales Protegidas. Análisis de la actividad turística en áreas Naturales Protegidas", tesis de maestría, Instituto Politécnico Nacional, México.

Burton, Fiona (1998), "Can Ecotourism objectives be achieved?", Annals of Tourism Research, 25 (3), Universidad de Wisconsin-Stout, Menomonie, pp. 742-746.

Carabias-Lillo, Julia, Enrique Provencio, Javier de la Maza Elvira y Francisco Javier Jiménez González (1999), Programa de Manejo Reserva de la Biosfera La Encrucijada, Instituto Nacional de EcologíaSemarnap, México.

Ceballos-Lascuráin, Héctor (1998), Ecoturismo, naturaleza y desarrollo sostenible, Diana, México.

Chambers, W. Bradnee y Jessica F. Green (2005), "Introduction: toward an effective framework for sustainable development", en W. Bradnee Chambers y Jessica F. Green (eds.), Reforming international environmental governance: from institutional limits to innovative reforms, United Nations University Press, Nueva York, pp. 1-12.

Chambers, Robert (1995), "Poverty and livelihoods: whose reality count?", Environment and Urbanization, 7 (1), International Institute for Environment and Development, Londres, pp. 173-204.

Chambers, Robert (2004), "Ideas for development: reflecting forward", en Institute of Development Studies, Working Paper, vol. 238, pp. $I-V I$, Institute of Development Studies, Brighton, pp. 1-40.

Conanp (Comisión Nacional de Áreas Naturales Protegidas) (2007), Programa Nacional de Áreas Naturales Protegidas, SemarnatConanp.

Coneval (Comisión Nacional de Evaluación de la Política de Desarrollo Social) (2009), "Reporta Coneval cifras de pobreza por ingresos 2008”, Comunicado de Prensa núm. 006/09, Coneval, México. 
Córdoba-y Ordóñez, Juan, Ana García de Fuentes, Matilde Córdoba Azcárate y María Esther Ayala Arcipreste (2004), "Efectos locales de políticas globales: Celestún y 'su' Reserva de la Biosfera (Yucatán, México)”, Anales de Geografía, 24, Universidad Complutense, Madrid, pp. 55-78.

Daltabuit-Godás, Magalí, Luz María Vázquez, Héctor Cisneros y Gregorio A. Ruiz (2006), El turismo costero en la ecorregión del Sistema Arrecifal Mesoamericano, Universidad Nacional Autónoma de México-Centro Regional de Investigaciones Multidisciplinarias, Cuernavaca.

DFID (Departament for Internacional Development) (1999), Hojas orientativas sobre los medios de vida sostenibles, Marco, DFID, Londres.

Epler-Wood, Megan (1998), "Respuesta al desafío global de la participación comunitaria en el ecoturismo: estudios y lecciones del Ecuador", Documento de Trabajo de América Verde 2b, The Nature Conservancy, Arlington, Virginia.

Escobar, Arturo (1996), La invención del Tercer Mundo. Construcción y deconstrucción del desarrollo, Norma, Bogotá.

Evans, Peter (2002), "Collective capabilities, culture and Amartya Sen's development as freedom", Studies in Comparative International Development, 37 (2), Rutgers University, New Brunswick, pp. 54-60.

Ferreira-de Faria, Ivani (2005), "Ecoturismo: etnodesenvolvimento e inclusão social no Amazonas", Pasos. Revista de Turismo y Patrimonio Cultural, 3 (1), Universidad de La Laguna, Tenerife, pp. 63-77.

Flores, Murilo (2007), "La identidad cultural del territorio como base de una estrategia de desarrollo sostenible”, Revista Ópera, 7 (7), Universidad Externado, Bogotá, pp. 35-54.

Hernández-Cruz, Rosa E., Eduardo Bello Baltazar, Guillermo Montoya Gómez y Erin I. J. Estrada Lugo (2005), “Adaptaciones sociales y ecoturismo en la Selva Lacandona", Annals of Tourism Research, 7 (2), Universidad de las Islas Baleares, Palma, pp. 236-254.

Holland, Jenny, Michael Burian y Louise Dixey (2003), "Diversifying the product and expanding the benefits in rural Uganda and the Czech 
Republic", Pro-Poor Tourism (РPT) Working Paper, núm. 12, UK Department for International Development, Londres, pp. 1-38.

INEGI-Inafed (Instituto Nacional de Estadística, Geografía e InformáticaInstituto Nacional para el Federalismo y el Desarrollo Municipal) (2000), Sistema Nacional de Información Municipal, INEGI-Inafed, Aguascalientes, México.

INEGI-ITER (Instituto Nacional de Estadística, Geografía e InformáticaSistema de Integración Territorial) (2005), Conteo municipal, INEGI, Aguascalientes, México.

Jones, Samantha (2005), "Community-based ecotourism. The significance of social capital”, Annals of Tourism Research, 32 (2), Universidad de Wisconsin-Stout, Menomonie, pp. 303-324.

Li, Wenjun y Nianyong Han (2000), "Ecotourism management in China’s Nature Reserve", Ambio, 30 (1), Royal Swedish Academy of Sciences, Estocolmo, pp. 62-63.

Liu, Zhenhua (2003), "Sustainable Tourism Development: a critique", Journal of Sustainable Tourism, 11 (6), Clavedon, Londres, pp. 459-475.

López-Pardo, Gustavo y Bertha Palomino Villavicencio (2008), "Políticas públicas y ecoturismo en comunidades indígenas de México", Teoría y Praxis, 5, Universidad de Quintana Roo, Cozumel, pp. 33-50.

Magaña-Carrillo, Irma (2009), "La política turística en México desde el modelo de calidad total: un reto de competitividad", Economía, Sociedad y Territorio, 9 (30), El Colegio Mexiquense, Zinacantepec, pp. 515-544.

March-Mifsut, Ignacio José y Alejandro Flamenco Sandoval (1996), Evaluación rápida de la deforestación en las áreas naturales protegidas de Chiapas (1970-1993), El Colegio de la Frontera Sur-The Nature Conservancy-usaid, San Cristóbal de Las Casas.

McLaren, Deborah (1998), Rethinking tourism and ecotravel. The paving of paradise and What you can do to stop it, Kumarian Press, Bloomfield. 
Mediano-Serrano, Lucía y Azucena Vicente Molina (2002), "Análisis del concepto de turismo rural e implicaciones de marketing", Boletín Económico de ICE, 2741, Secretaría de Comercio-Ministerio de Economía y Hacienda, Madrid, pp. 25-36.

Milton, Kay (1996), Environmentalism and culture theory. Exploring the role of anthropology in environmental discourse, Routledge, Londres.

Montañez-Gómez, Gustavo y Ovidio Delgado-Mahecha (1998), "Espacio, territorio y región: conceptos básicos para un proyecto nacional", Cuadernos de Geografía, 7 (1-2), Universidad Nacional de Colombia, Bogotá, pp. 120-134.

Moreno, Peter S. (2005), "Ecotourism along the Meso-American Caribbean Reef: the impacts of foreign investment", Human Ecology, 33 (2), Kluwer Academic, Nueva York, pp. 217-244.

Naughton-Treves, Lisa, Margaret Buck Holland y Katrina Brandon (2005), "The role of protected areas in conserving biodiversity and sustaining local livelihoods", Annual Review of Environmental and Resources, 30, Annual Review, pp. 219-232, <http//www. arjournals.annualreviews.org>, 28 de junio de 2006.

Oliveira-Santos, Eurico de y Carlos Ernesto González-Esquivel (2008), "El turismo en el espacio rural en la mitad sur de Río Grande do Sul, Brasil (1997-2005)", Economía, Sociedad y Territorio, 8 (27), El Colegio Mexiquense, Zinacantepec, pp. 721-738.

Paniagua-Mazorra, Ángel (2008), "La individualización del mundo rural. Dimensiones analíticas para ¿un concepto generalizable?”, Economía, Sociedad y Territorio, 8 (27), El Colegio Mexiquense, Zinacantepec, pp. 639-659.

Parra-Vázquez, Manuel Roberto, Obeimar Balente Herrera Hernández, Margarita Haydee Huerta Silva, Pedro Pablo Ramos Pérez, Iris Josefina Liscovsky e Ivonne Sánchez Vázquez (2011), Manual de diagnóstico participativo para la planeación comunitaria, El Colegio de la Frontera Sur, San Cristóbal de Las Casas (en prensa).

Pastor-Alfonso, María José (2003), "Turismo, cultura y medio ambiente", Pasos. Revista de Turismo y Patrimonio Cultural, 1 (2), Universidad de La Laguna, Tenerife, pp. 145-153. 
Ramsar (2010), "The list of wetlands of international importance", Ramsar List, Convención Ramsar, <http://www.ramsar.org/cda/es/ramsardocuments-list-ramsar-list-of/main/ramsar/1-31-218\%5E7791_ 4000_2>, 5 de febrero de 2010.

Reygadas, Luis, Teresa Ramos, Guillermo Montoya, Francisco Hernández y Alfredo Velazco (2006), "Estilos de manejo y gestión de proyectos ecoturísticos en la Selva Lacandona de Chiapas, México", en Rosana Guevara Ramos (coord.), Estudios multidisciplinarios en turismo, Secretaría de Turismo, México, pp. 71-102.

Ross, Sheryl y Geoffrey Wall (1999), "Ecotourism: towards congruence between theory and practice", Tourism Management, 20, Butterworth Scientific, Guildford, pp. 123-132.

Salinas-Chávez, Eduardo y José Alberto La O Osorio (2006), “Turismo y sustentabilidad: de la teoría a la práctica en Cuba", Cuadernos de Turismo, 17, Universidad de Murcia, Murcia, pp. 201-221.

Sánchez, Liliana María (2007), "Fragmentación social y planeación territorial", Revista Bitácora Urbano Territorial, 1 (11), Universidad Nacional de Colombia, Bogotá, pp. 28-39.

Sen, Amartya (1997), "Human capital and human capability", World Development, 25 (12), McGill University, Montreal, pp. 1959-1961.

Sen, Amartya (1999), "Health in development", Bulletin of the World Health Organization, 77 (8), World Health Organization, Génova, pp. 619-623.

Sen, Amartya (2002), "Basic education and human security", Workshop "Basic Education and Human Security", Comission of Human Security, Kolkata, India, 2-4 de enero de 2002.

Scheyvens, Regina (1999), "Ecotourism and the empowerment of local communities", Tourism Management, 20, Butterworth Scientific, Guildford, pp. 245-249.

Shärer, René (2003), “Turismo sustentável: um estudo de caso sobre a experiência da comunidade de prainha do Canto Verde no litoral do Ceará", Pasos. Revista de Turismo y Patrimonio Cultural, 1 (2), Universidad de La Laguna, Tenerife, pp. 231-242. 
Serrano-Barquín, Rocío del Carmen (2008), "Hacia un modelo teóricometodológico para el análisis del desarrollo, la sostenibilidad y el turismo", Economía, Sociedad y Territorio, 8 (26), El Colegio Mexiquense, Zinacantepec, pp. 313-356.

Skockzek, María (2003), "El papel del turismo rural en las transformaciones del campo, experiencias de los países andinos y el caso de México", Actas Latinoamericanas de Varsovia, 26, Universidad de Varsovia, Varsovia, pp. 63-72.

Tovilla-Hernández, Cristian (2007), Estudio diagnóstico: situación actual de los manglares en la Reserva de la Biosfera La Encrucijada y su área de influencia Chiapas, México: transferencia y sociabilización del conocimiento, El Colegio de la Frontera Sur, San Cristóbal de Las Casas.

Vera-Rebollo, J. Fernando (2006), "Agua y modelo de desarrollo turístico: la necesidad de nuevos criterios para la gestión de los recursos", Boletín de la AGE, 42, Tarragona, pp. 155-178.

Recibido: 27 de abril de 2010. Reenviado: 12 de octubre de 2010. Aceptado: 3 de febrero de 2011.

Iris Josefina Liscovsky. Es doctora en ciencias geológicas por la Facultad de Ciencias Exactas, Físicas y Naturales de la Universidad Nacional de Córdoba (Argentina); bióloga y profesora en ciencias biológicas en dicha facultad y actualmente realiza el doctorado en ciencias en ecología y desarrollo sustentable en El Colegio de la Frontera Sur (México). Fue condecorada con la Mención Especial del Premio Universidad 2001, por la carrera de ciencias biológicas (FCEFyN-UNC). Entre los años 2001 y 2007 se desempeñó como auxiliar docente y jefe de trabajos prácticos en la FCEFyn-UNC. Su línea de estudio actual se centra en el análisis de las políticas ambientales en relación con los medios de vida locales, con énfasis en el ecoturismo. Algunas de sus publicaciones en coautoría son: "Flower vascularisation in Solanaceae: a particular pattern in Metternichia J. G. Mikan”, Adansonia, 3 (31), Museo Nacional de Historia Natural, París, pp. 413-425 (2009); "Anatomía comparativa de hoja y tallo en los representantes argentinos de Cestreae G. Don (Solanacea)", Gayana Botánica, 62 (1), Universidad de Concepción, Concepción, pp. 33-43 (2005); "Crecimiento secundario atípico del tallo de Datura ferox (Solanaceae)", Kurtziana, 29 (1), Museo Botánico, Universidad Nacional de Córdoba, Córdoba, pp. 7-13 (2001). 
Manuel Roberto Parra-Vázquez. Es doctor en economía por la Universidad Nacional Autónoma de México; maestro en ciencias agrícolas por El Colegio de de Postgraduados de Chapingo e ingeniero agrónomo zootecnista por la Escuela Nacional de Agricultura. Es profesor e investigador en la Universidad Autónoma Chapingo, el Colegio de Postgraduados de Chapingo y El Colegio de la Frontera Sur. Investiga sobre los procesos de diseño de políticas públicas para el desarrollo local, coordina investigaciones sobre desarrollo rural en áreas campesinas del centro y sureste de México con un enfoque territorial y bajo una perspectiva interdisciplinaria. Su objetivo es propiciar, mediante un aprendizaje social, el establecimiento de sistemas de manejo sustentable de la tierra basados en los saberes de todos los participantes. Entre sus publicaciones sobresalen: en coautoría, Los Altos de Chiapas: agricultura y crisis rural, Los recursos naturales, t. 1, Ecosur-Semarnap, San Cristóbal de Las Casas, Chiapas (1997); "Restauración de bosques en territorios indígenas de Chiapas. Modelos ecológicos y estrategias de acción”, Boletin de la Sociedad Botánica de México, 80, Sociedad Botánica de México, México, pp. 11-23 (2007); "Estrategia regional de desarrollo comunitario del proyecto Pades", en Germán Martínez Velasco (coord.), Población y ambiente: tres estudios para el desarrollo sustentable en la Selva Lacandona, Consejo Estatal de Población-unfpa, Tuxtla Gutiérrez, Chiapas, pp. 205-301 (2008); "Forestería comunitaria y desarrollo de instituciones locales: el caso de la comunidad agraria Teopisca", Economía, Sociedad y Territorio 9 (30), El Colegio Mexiquense, Zinacantepec, pp. 349-395 (2009).

Eduardo Bello-Baltazar. Es doctor en antropología social por la Universidad Iberoamericana; maestro en ciencias con especialidad en desarrollo rural por el Colegio de Posgraduados e ingeniero agrónomo por la Universidad Autónoma Metropolitana. Es investigador nivel I en el Sistema Nacional de Investigadores (sNI). Actualmente labora en El Colegio de la Frontera Sur, San Cristóbal de Las Casas, donde coordina la Red de Espacios de Innovación Socioambiental (Redisa). Investiga las implicaciones sociales del manejo de los recursos naturales en temas como: organización social y territorio, comunidad y planes de manejo del bosque (ecoturismo, silvicultura, productos no convencionales), ritualidad y redes sociales, leyes y normas locales. Entre sus publicaciones recientes, en coautoría, están: "Experiencias, aprendizajes y diferencias en la toma de decisiones de dos grupos campesinos mayas en la adopción de tecnologías agrícolas en Sahcabá, Hocabá, Yucatán, México”, Estudios de Antropología Biológica, XIV (II), Universidad Nacional Autónoma de México, México, pp. 629-647 (2009); "Forestería comunitaria y desarrollo de instituciones locales: el caso de la comunidad agraria Teopisca", Economía, Sociedad y 
Territorio, Ix (30), El Colegio Mexiquense, Zinacantepec, pp. 349-395 (2009); "Religión y espacio social: una microrregión maya de Quintana Roo", en Julio Robertos, Ever Canul y Manuel Buenrostro (eds.), Mayas modernos de Quintana Roo, Universidad de Quintana Roo-Centro de Estudios Interculturales-Plaza y Valdés, pp. 25-55 (2008).

Ana Minerva Arce-Ibarra. Es doctora en estudios interdisciplinarios por la Universidad de Dalhousie (Canadá); maestra en biología marina por el Cinvestav-Mérida y licenciada en biología pesquera por la Universidad Autónoma de Sinaloa. Es miembro del Comité de Evaluación de Proyectos Compact-pnud, Península de Yucatán. Su línea de investigación se centra en el análisis de las pesquerías artesanales por medio de estudios interdisciplinarios. Entre sus publicaciones destacan, en coautoría: "Nonmanagement of natural resources: The case of inland fisheries in the Mayan Zone, Quintana Roo, Mexico", Human Ecology, 36, Kluwer Academic, Nueva York, pp. 853-860 (2008); "Inland fisheries of the Mayan Zone in Quintana Roo: Using a combined approach to fishery assessment for data-sparse fisheries", Fisheries Research, 91, Elsevier, Amsterdam, pp. 151-159 (2008); "Linking social and natural sciences methods using Mind Maps: A case study of human-nature interactions in Mexico's Lowland Maya area", The International Journal of Interdisciplinary Social Sciences, 2, Common Ground, Melbourne, pp. 39-52 (2007). 